\title{
Absence of chloride intracellular channel 4 (CLIC4) predisposes to acute kidney injury but has minimal impact on recovery
}

John C Edwards ${ }^{1,2^{*}}$, Jonathan Bruno ${ }^{1,2}$, Phillip Key ${ }^{2}$ and Yao-Wen Cheng ${ }^{1}$

\begin{abstract}
Background: CLIC4, a member of the CLIC family of proteins, was recently demonstrated to translocate to the nucleus in differentiating keratinocytes where it potentiates TGF $\beta$-driven gene regulation. Since TGF $\beta$ signaling is known to play important roles in the fibrotic response to acute kidney injury, and since CLIC4 is abundantly expressed in kidney, we hypothesized that CLIC4 may play a role in the response to acute kidney injury.

Methods: Previously described Clic4 null mice were analyzed for the effect of absence of CLIC4 on growth, development and response to kidney injury. Kidney size, glomerular counts and density of peritubular capillaries of matched WT and Clic4 null mice were determined. Cohorts of WT and Clic4 null mice were subjected to the folic acid model of acute kidney injury. Extent of acute injury and long term functional recovery were assessed by plasma blood urea nitrogen (BUN); long term fibrosis/scarring was determined by histochemical assessment of kidney sections and by residual renal mass. Activation of the TGF $\beta$ signaling pathway was assessed by semiquantitative western blots of phosphorylated SMADs 2 and 3.
\end{abstract}

Results: CLIC4 is abundantly expressed in the apical pole of renal proximal tubule cells, and in endothelial cells of glomerular and peritubular capillaries. CLIC4 null mice are small, have smaller kidneys with fewer glomeruli and less dense peritubular capillary networks, and have increased proteinuria. The Clic4 null mice show increased susceptibility to folic acid-induced acute kidney injury but no difference in recovery from acute injury, no nuclear redistribution of CLIC4 following injury, and no significant difference in activation of the TGF $\beta$-signaling pathway as reflected in the level of phosphorylation of SMADs 2 and 3.

Conclusions: Absence of CLIC4 results in morphologic changes consistent with its known role in angiogenesis. These changes may be at least partially responsible for the increased susceptibility to acute kidney injury. However, the absence of CLIC4 has no significant impact on the extent of functional recovery or fibrosis following acute injury, indicating that CLIC4 does not play a major non-redundant role in the TGF $\beta$ signaling involved in response to acute kidney injury.

Keywords: CLIC4, Acute kidney injury, Glomerular endowment, Peritubular capillary network, Transforming growth factor $\beta$

\footnotetext{
* Correspondence: Edwardjc@slu.edu

${ }^{1}$ Kidney Center and the Department of Internal Medicine, University of North Carolina, Chapel Hill NC, USA

${ }^{2}$ Division of Nephrology, Department of Internal Medicine, Saint Louis University, St. Louis, MO, USA
} 


\section{Background}

Genetically defined mice are powerful tools that are capable of identifying roles of specific proteins in physiologic processes. However, interrelations between genes and complex phenotypes can be indirect, multifaceted, and challenging to unravel. One such complex phenotype is the susceptibility to and recovery from acute kidney injury (reviewed in [1-4]). Toxic or ischemic injury to kidney tubules triggers a cascade of events which include apoptosis and sloughing of injured cells, "dedifferentiation" of surviving cells which then proliferate and migrate to repopulate the tubule, and finally redifferentiation [1]. This process involves mediators generated by both endogenous kidney cells and by infiltrating white blood cells which are instrumental in both the initial injury and the long term recovery [1-4]. Recovery may be incomplete and accompanied by significant interstitial fibrosis and scarring that leads to chronic kidney disease and increased susceptibility to future renal insults [2]. Injury and recovery is not limited to the epithelial cells, but also involves the endothelial cells of the peritubular capillaries. Failure of recovery of this compartment results in rarefication of the peritubular capillary network and is associated with poor functional renal recovery [5,6]. Identification of genes and proteins involved in both susceptibility to acute injury and subsequent chronic kidney scarring may lead to insights into treatment and/or prevention of these important human disease states.

CLIC4 is a member of the CLIC family of proteins which were originally identified as chloride channels of intracellular membranes $[7,8]$. Over the years, a variety of diverse yet not entirely mutually consistent data have been presented about CLIC4. Thus CLIC4 has been reported to be in endoplasmic reticulum, trans-Golgi network, caveolae, mitochondria, dense-core secretory vesicles in the central nervous system, and nuclei of differentiating keratinocytes [9-13]. Purified CLIC4 has been reported to function as a channel in vivo but details of channel properties are not consistent among the reports $[14,15]$. It has variously been proposed to function as a channel of intracellular membranes [16,17], as a regulator of apoptosis [18-20], as a cytoskeletal component $[21,22]$, and as a modulator of gene expression during differentiation of myofibroblasts [23]. Although the function of CLIC4 is still uncertain, it has been most convincingly implicated in two distinct cellular processes: the intracellular membrane trafficking leading to tubulogenesis of endothelial cells $[17,24,25]$, and potentiation of transforming growth factor $\beta$ (TGF $\beta$ ) signaling during keratinocyte differentiation and wound healing in the skin $[23,26,27]$.

Angiogenesis and TGF $\beta$ signaling are both known to be relevant to acute kidney injury. Angiogenesis is critical to development of the kidney, particularly in formation of glomeruli, and glomerular endowment is known to affect susceptibility to acute kidney injury (AKI); peritubular capillary injury is an important component of the initial injury and angiogenesis of this compartment in response to acute injury may aid in recovery $[6,28]$. TGF $\beta$ signaling has long been recognized as an important component in the response to acute kidney injury, playing a role in driving the fibrosis and scarring following injury [29-31]. Based on these observations, our central hypothesis is that CLIC4 is important to the susceptibility and response to kidney injury.

We have previously reported the generation of mice in which the gene for CLIC4 has been disrupted [17]. We chose to use our Clic4 null mice to investigate the role of CLIC4 in the kidney. In the results presented here, we find that CLIC4 is expressed in proximal tubule cells as well as endothelial cells of both peritubular and glomerular capillaries. Clic4 null mice have smaller kidneys with fewer glomeruli and less dense peritubular capillary network, consistent with a role for CLIC4 in angiogenesis during development of the kidney. The Clic4 null mice were found to have albuminuria but do not have prominent glomerular ultra-structural abnormalities that are often seen in proteinuric states. Clic4 null mice show increased susceptibility to folic acid-induced acute kidney injury. However we did not find compelling evidence for a role for CLIC4 in either the functional recovery or the fibrosis and scarring following injury, indicating that CLIC4 does not play a critical nonredundant role in the TGF $\beta$ signaling that drives scarring following injury.

\section{Methods}

\section{Mice}

Generation of the mice carrying a disrupted Clic4 gene has been previously described [17]. Male and female Clic4 $4^{(-)}$mice in the CD1 background were crossed with CD1 WT mice (Charles River) to generate newly outbred $\mathrm{Clic}^{(+/-)}$mice. Multiple pairs of non-sibling newly outbred $\mathrm{Clic}^{(+/-)}$mice were mated and $\mathrm{Clic} 4^{(-/-)}$ and $\mathrm{Clic}^{(+++)}$mice selected from this F1 generation. Non-sibling F1 Clic4 $4^{(++)}$or $\mathrm{Clic}^{(-/-)}$mice were mated to generate the F2 $\mathrm{Clic}^{(+/+)}$(wild type, WT) and Clic4 $4^{(-/-)}$ (Clic4 null) mice that were used in all these experiments. Animals to be studied were randomly chosen from the available population. The Clic4 genotype of each mouse was confirmed by polymerase chain reaction at the end of each experiment using DNA prepared from tail snips as previously described[17]. Mice were maintained in conventional static microisolator cages (1-5 mice per cage) with cob bedding and a paper supplement for enrichment and nesting, light/dark cycles of 12 hours, temperate regulated at $70 \mathrm{~F}$, with continuous access to water and standard mouse chow. Animal health was actively monitored 
by husbandry and veterinary staff. The animal facilities are registered with the USDA, follow the regulations set out in the US Government Principles, the Guide for Care and Use of Laboratory Animals and the US Public Health Service Policy as required by National Institutes of Health and the Office of Laboratory Animal Welfare, and are fully accredited by the Association for Assessment and Accreditation of Laboratory Animal Care International. All mouse studies were in compliance with protocols approved by the Institutional Animal Care and Use Committees of the University of North Carolina at Chapel Hill and/or St. Louis University, as appropriate.

\section{Antibodies and lectins}

AP255 and AP1089, the affinity-purified rabbit polyclonal antibodies to CLIC4 and CLIC1, respectively, have been previously described $[17,32]$. Commercial antibodies were as follows: Goat polyclonal antibody to mouse albumin, Bethyl Labs (Montgomery TX) \#A90134; rat monoclonal antibody to CD31 clone MEC13.3, Pharmingen (San Jose, CA) \#550274; mouse monoclonal antibody to PCNA, Cell Signaling Technology (Danvers, MA) \#2586; rabbit monoclonal antibody to Smad2/3, Cell Signaling Technology \#8685; rabbit monoclonal antibody to phospho-Smad2/3, Sigma-Aldrich \#SAB4504208; mouse monoclonal antibody to GAPDH, Santa Cruz Biotechnology (Santa Cruz, CA) \#SC-32233; goat polyclonal antibody to CLIC5, Santa Cruz Biotechnology \#SC-65041 Alexa Fluor 488 anti rat IgG, Life Technologies (Grand Island, NY); Cy5 goat anti rabbit IgG, Jackson Labs (Bar Harbor, ME) \#111-175-144; FITC-lectin from Lotus tetragonolobus (LTA), Vector Labs (Burlingame CA) \#FL1321; Alexa Fluor 594-isolectin B4 from Griffonia simpicifolia (IB4), Life Technologies, \#I21413; HRP-conjugated secondary antibodies, Thermo Scientific Pierce.

\section{Immunolocalization}

Adult mice were anticoagulated with 500 units of heparin by intraperitoneal injection 10 minutes prior to euthanasia by $\mathrm{CO}_{2}$ inhalation. The mice were perfused with 30 $50 \mathrm{ml}$ of phosphate buffered saline through the left ventricle via a short-bevel $22 \mathrm{Ga}$. needle and exiting the lacerated right atrium. The mice were then perfused with $30 \mathrm{ml}$ of fresh PLP fixative (2\% paraformaldehyde, $75 \mathrm{mM}$ sodium phosphate, $75 \mathrm{mM}$ lysine, $10 \mathrm{mM}$ sodium periodate, $\mathrm{pH}$ 7.4). The kidneys were removed, divided into 3-4 pieces, and further fixed in PLP for 24 hours. For extended storage, the fixative was replaced with $0.05 \%$ paraformaldehyde in PBS to minimize antigen masking.

Sections $100 \mu \mathrm{m}$ thick were made using a Leica VT 1200 vibratome. Sections were washed in PBS and blocked and permeabilized for 2 hours in an excess volume of Superblock (Thermo Scientific Pierce \#37535) supplemented with $0.5 \% \quad(\mathrm{v} / \mathrm{v})$ Triton X-100. All subsequent antibody incubations and washes were performed in 15-50 $\mu \mathrm{l}$ drops on hydrophobically-masked slides in TNTFB2 ${ }^{+}$(50 mM tris[hydroxymethyl]aminomethane, $200 \mathrm{mM} \mathrm{NaCl}, 0.1 \%$ coldwater fish skin gelatin, $1 \%$ bovine serum albumin, $0.05 \%$ Tween-20, $0.5 \mathrm{mM} \mathrm{MgCl}_{2}, 0.5 \mathrm{mM} \mathrm{MnCl}_{2}, 0.5 \mathrm{mM} \mathrm{CaCl}_{2}, \mathrm{pH} 7.5$ ). Incubation with the primary AP255 antibodies was done overnight at $4^{\circ} \mathrm{C}$; samples were washed six times over more than one hour; incubation with the secondary antibody and lectins was for two hours at room temperature (cy5-conjugated goat anti rabbit, $20 \mathrm{ug} / \mathrm{ml}$; FITC conjugated LTA, $40 \mathrm{ug} / \mathrm{ml}$; and Alexa Fluor 594-conjugated IB4, $40 \mathrm{ug} / \mathrm{ml}$ ) followed by washing as before. Because of LTA incompatibility with glycerol mounting compounds, final mounts were made in $100 \mathrm{mM}$ tris[hydroxymethyl] aminomethane, $100 \mathrm{mM} \mathrm{NaCl}, 10 \mathrm{mM}$ ascorbic acid, $0.5 \mathrm{mM} \mathrm{MgCl}_{2}, 0.5 \mathrm{mM} \mathrm{MnCl}, 0.5 \mathrm{mM} \mathrm{CaCl} 2$, and $500 \mathrm{ng} / \mathrm{ml} \mathrm{4}$ ',6-diamidino-2-phenylindole (DAPI) pH 7.5. Number 1.5 coverslips were sealed using quick-setting epoxy and imaged using an Olympus Fluoview 1000 scanning confocal microscope in the Research Microscopy Core at St. Louis University School of Medicine.

\section{Glomerular counts}

Glomeruli were labeled with Alcian Blue using a variant of established methods [33,34]. The formulation of the dye known as Alcian Blue has changed since its original manufacture [35]. Unlike the original, the currently available compound is not soluble in saline. Alcian Blue 8GS (Applichem, Darmstadt Germany) was dissolved at $5 \mathrm{mg} /$ $\mathrm{ml}$ in $5 \%$ dextrose, centrifuged at $12,000 \mathrm{~g}$ for 10 minutes, and then passed through a 0.22 micron filter. Mice were given a subcutaneous injection of 150 units of heparin 10 minutes prior to euthanization by $\mathrm{CO}_{2}$ inhalation. Mice were perfused through the left ventrical with $10 \mathrm{ml}$ of PBS, followed by $10 \mathrm{ml}$ of $5 \%$ dextrose, $4 \mathrm{ml}$ of the Alcian Blue solution, and finally 15 more $\mathrm{ml}$ of $5 \%$ dextrose. The kidneys were excised and, after removal of the capsule, cut in half, soaked in $5 \mathrm{ml}$ of $1 \%$ ammonium hydroxide for 2 hours, then transferred to $5 \mathrm{ml}$ of $6 \mathrm{~N} \mathrm{HCl}$ and incubated at $37 \mathrm{C}$ for 1.5 hours. The resulting suspension was vigorously vortexed to break up clumps, $25 \mathrm{ml}$ of water was added and the suspension was placed at $4{ }^{\circ} \mathrm{C}$ overnight. $200 \mu \mathrm{l}$ aliquots of the macerated kidney suspension were placed on a grid and glomeruli in each aliquot counted under a low power objective. Glomeruli were readily distinguished by their blue staining. Additional aliquots were assessed until a minimum of 500 glomeruli from each pair of kidneys were counted. The person counting was blinded to the genotypes of the samples.

\section{Peritubular capillary density}

Frozen unfixed longitudinal sections through the center of the kidney were prepared from a set of age- and sex- 
matched WT and Clic4 null mice. Sections were fixed on the slide with $100 \%$ methanol at $-20^{\circ} \mathrm{C}$ for 5 minutes. The sections were probed with rat monoclonal antibody to CD31, followed by an Alexa Fluor488-conjugated anti-rat IgG antibody. A set of contiguous images were obtained which spanned the length of the kidney. Images from all mice were collected and processed identically. ImageJ software (http://imagej.nih.gov/ij/) was used to determine the fractional surface area of each section that stained for CD31, after excluding glomeruli, large vessels, artifacts, and edges. The person carrying out the image analysis was blinded to the genotypes of each set of sections.

\section{Induction of acute kidney injury}

Age- and sex-matched 6 to 12 week old mice were subjected to folic acid-induced acute kidney injury using an established protocol [36-38]. Within a few days before the induction of injury, a blood sample was obtained for initial blood urea nitrogen (BUN) determination. Unless otherwise noted, a sterile solution of $30 \mathrm{mg} / \mathrm{ml}$ folic acid (Sigma Aldrich, St. Louis MO Cat \# F8758) in 300 mM bicarbonate was administered as a single intraperitoneal injection at a dose of $250 \mathrm{mg}$ per $\mathrm{kg}$ body weight. Treated mice were maintained in group cages with ad libitum access to water and standard mouse chow. Blood samples were obtained by tail vein nicking at 2,7 , and 21 days after the folic acid injection.

\section{Measurement of renal fibrosis following injury}

Mice were euthanized on day 21 following folic acid treatment. Formalin fixed, paraffin embedded midline longitudinal kidney sections were stained with Mason's trichrome. Standard light micrographs were collected with a $4 \times$ objective. A composite image covering the entire section was generated from individual images. ImageJ software was used to determine the fractional area of each section that stained blue.

\section{Semi-quantitative western blotting}

Kidney homogenates were generated by grinding freshly isolated kidney in RIPA buffer (1/2 kidney in $0.5 \mathrm{ml}$ ) supplemented with Mammalian Proteinease Inhibitor Cocktail (Sigma-Aldrich \#P8340) and Phosphatase Inhibitor Cocktail 3 (Sigma-Aldrich \#P0044). Insoluble material was removed by centrifugation. Total protein concentration was determined using BCA reagent (Thermo Scientific Pierce, Rockford, IL). Fifty micrograms of each sample were separated on 10\% SDS-PAGE gels, blotted to PVDF membrane, blocked with 5\% nonfat dried milk in TNT (200 mM NaCl, $50 \mathrm{mM}$ Tris[hydroxymethyl] aminomethane, $0.1 \%$ Tween $20 \mathrm{pH}$ 7.5) and probed sequentially with antibodies to CLIC4, CLIC1, CLIC5, SMAD2/3, phosphorylated SMAD2/3, PCNA, and GAPDH.
Proteins were detected with HRP-conjugated secondary antibody and Supersignal Extended West Dura chemiluminescent reagent (Thermo Scientific Pierce), using a Protein Simple digital luminescence imager. Membranes were stripped between each iteration of detection by incubation in $2 \%$ SDS, $50 \mathrm{mM}$ Glycine $\mathrm{pH} 2.5$ for 30 minutes at room temperature, followed by washing with TNT and reblocking with $5 \%$ nonfat dry milk in TNT. The intensity of luminescence signals were normalized to the GAPDH signal in the same lane.

\section{Clinical lab values}

Blood and urine clinical lab testing including BUN, plasma albumin, urine total protein, and urine creatinine was performed using the services of the animal core lab at the University of North Carolina. Blood and urine $\beta 2$ microglobulin was determined using an ELISA-based kit from Uscn Life Sciences (Houston, TX, cat. \# E90260Mu). Urine albumin concentration was determined by quantitative western blotting as follows. Urine containing $1.5 \mu \mathrm{g}$ of creatinine from each mouse was separated by SDS-PAGE and blotted to nitrocellulose. A series of standards diluted from mouse plasma with known albumin concentration was run on the same gel. The blot was probed with an antibody to mouse albumin, developed with HRPconjugated secondary antibody, and quantitatively detected by chemiluminescence using a Protein Simple digital imager.

\section{Statistics}

Unless otherwise noted, values are reported as means \pm the standard error of the mean. Wilcoxon rank sum test was used to determine the significance of the difference in the 48 hour BUN values and 21 day fractional scarring between WT and Clic4 null mice since these data are clearly not normally distributed. P values for differences among proportions were determined using two-tailed Fisher's exact test. Differences of intensity of western blot signals were analyzed using Analysis of Variance methods since these data contained multiple equivalent groups. All other comparisons were analyzed with two tailed, unpaired Student's T-test. All statistical methods were as described by Armitage [39].

\section{Results}

\section{Distribution of CLIC4 in normal mouse kidney}

Vibratome sections of kidney were prepared from 8 week old WT and Clic4 null male mice and stained with CLIC4 antibody plus lectin markers of endothelial cells (IB4) and proximal tubule brush border (LTA), as well as a nuclear marker (DAPI). Images were collected with confocal microscopy and shown in Figures 1, 2 and 3. Identically treated, stained, and imaged sections from Clic4 null mice served as the negative control and 


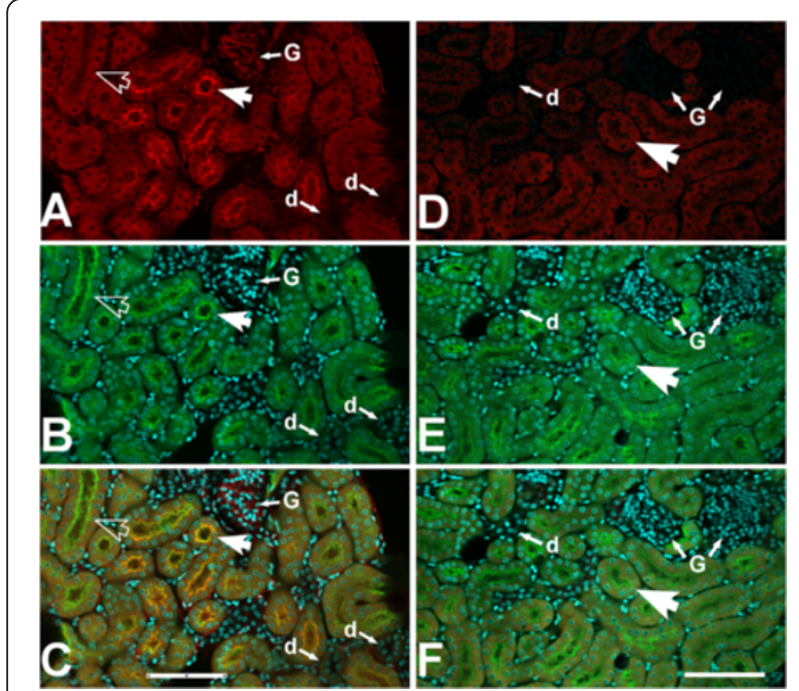

Figure 1 Immunolocalization of CLIC4 in mouse kidney, low power images. Vibratome sections of mouse kidney stained with antibody to CLIC4 (red) plus markers for the proximal tubule brush border (LTA, green), and nuclei (DAPI, cyan) were observed with a 20x objective under confocal microscopy. The panels on the left $(\mathbf{A}-\mathbf{C})$ are from a WT mouse, the panels on the right (D-F) are from a Clic4 null mouse. A and D: CLIC4 signal. B and E: Merged LTA (green) and DAPI (cyan) signals. $\mathbf{C}$ and $\mathbf{F}$ : Merged image with all signals. The large arrows indicate proximal tubules, identified by brush border staining with LTA. In panels $\mathbf{A}-\mathbf{C}$, the solid large arrow indicates a LTA-positive proximal tubule that shows apical staining for CLIC4; the open large arrow indicates a LTA-positive proximal tubule that does not show apical CLIC4 staining. Glomeruli are designated $\mathrm{G}$, distal (LTA-negative) tubules are designated $d$. The scale bar represents 100 microns.

showed no significant signal with the CLIC4 antibody. Figure 1 shows low power images of the cortical labyrinth stained with antibodies to CLIC4 (red) plus the proximal tubule brush border (green) and nuclear (cyan) markers. Images from the wild type mouse are on the left, identically processed images from the Clic4 null mouse on the right. Most of the tubules in the image are proximal tubules that are positive for the PTC brush border marker, LTA (green). A few LTA-negative distal nephron tubule cross sections are seen, labelled ' $d$ ' and glomeruli are labelled 'G'. CLIC4 is detected in a subset of the LTA-positive proximal tubule segments where it shows an apical distribution. The tubule segments which express apical CLIC4 most prominently tend to be near glomeruli, suggesting they likely represent earlier segments of the proximal tubule. Whether the proximal tubule cells without prominent apical staining express CLIC4 in a diffuse cytoplasmic pattern is uncertain since the signal in not markedly more intense than the background signal in the Clic4 null section. CLIC4 staining is also detectable in glomeruli and in an interstitial pattern consistent with the peritubular capillary network. CLIC4 signal is absent in the distal tubules. In the Clic4 null

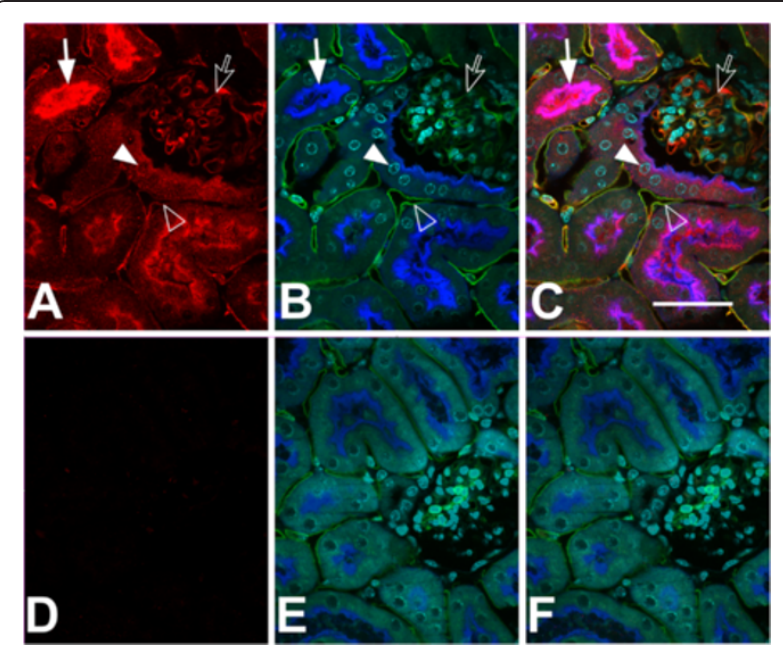

Figure 2 Immunolocalization of CLIC4 in mouse kidney, high power images. Vibratome sections stained with affinity-purified antibody to CLIC4 (red) plus markers for proximal tubule brush border (Lectin LTA, here shown in blue), endothelial cells (Lectin IB4, green), and nuclei (DAPI, cyan) were observed with a $60 \times$ objective under confocal microscopy. The upper set of images (A-C) are from a WT mouse, the lower set (D-F) are from a Clic4 null mouse. $\mathbf{A}$ and D (left): CLIC4 signal alone (red); $\mathbf{B}$ and $\mathbf{E}$ (center): merged image of the three markers (proximal tubule brush border in blue, endothelial cells in green, and nuclei in cyan); $\mathbf{C}$ and $\mathbf{F}$ (right): merged image of all signals. Solid arrow: colocalization of CLIC4 with LTA in proximal tubule brush border. Solid arrow head: CLIC4 signal in nucleus of a proximal tubule cell. Open arrow: colocalization of CLIC4 and IB4 in glomerular capillary loop. Open arrowhead: colocalization of CLIC4 and IB4 in peritubular capillary. Scale bar represents 50 microns.

mice, there is a low intensity diffuse signal in the proximal tubule cells, but the apical staining pattern and the glomerular and pertitubular staining patterns are absent.

Higher power images are presented in Figure 2, stained for CLIC4 (red), the proximal tubule brush border marker LTA (this time shown in blue), the endothelial marker IB4 (green) and the nuclear marker DAPI (cyan). Kidney from a wild type mouse is in the upper set of images, Clic4 null in the lower set. In epithelial cells, CLIC4 (red) is prominent in the proximal tubules, identified by brush border labeling with the lectin LTA (blue). Within the proximal tubule cells, CLIC4 is strikingly apically polarized and appears to be present in the brush border where it colocalizes with the LTA marker (solid arrow). In addition, it is present in the cytoplasm in a punctate pattern consistent with a vesicular distribution. CLIC4 signal is also found in nuclei at about the same abundance as in the surrounding cytoplasm and many nuclei have punctate staining (solid arrow head) that is not present in the Clic4 null controls. In addition to proximal tubule epithelium, CLIC4 signal is also abundant in endothelial cells of the peritubular capillary network (open arrowhead) and of the glomerular capillaries (open arrow) where it colocalizes with the 


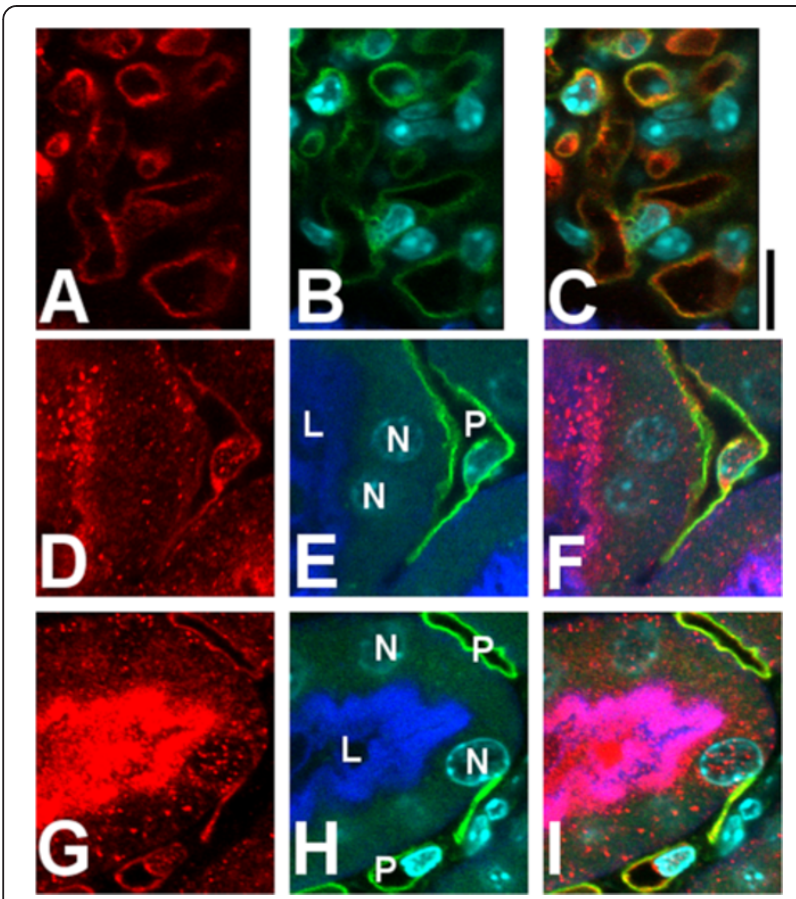

Figure 3 Higher magnification images of CLIC4 in WT kidney. Pseudocolor as in Figure 2. Upper set of images (A-C) shows glomerular capillary loops, lower sets (D-F and G-I) show a portion of a proximal tubule and underlying peritubular capillaries. Panels $\mathbf{A}$, D, and $\mathbf{G}$ (left column): CLIC4 signal alone; Panels B, E, and $\mathbf{H}$ (center column): merged image of the three markers (proximal tubule brush border in blue, endothelial cells in green, and nuclei in cyan); Panels $\mathbf{C}, \mathbf{F}$, and I (right column): merged image of all signals. Structures are indicated in the center image: $L$ indicates proximal tubule lumen, $N$ indicates proximal tubule cell nuclei, $\mathrm{P}$ indicates peritubular capillary. Note the close colocalization of CLIC4 (red) with IB4 (green) in both glomerular capillary loops (upper image set) and peritubular capillary (lower image sets). Also, note presence of CLIC4 (red) colocalizing with the brush border (blue) and in the nuclei (cyan) of the proximal tubule cells and in the nuclei of the peritubular capillary endothelial cells in the two lower image sets. Scale bar to the right of the upper panel represents 10 microns.

endothelial marker IB4 (green). Each of these CLIC4 signals is absent in the identically processed images from the Clic4 null kidney shown in the lower panel.

Higher magnification images are shown in Figure 3. In glomeruli (upper panel) the CLIC4 staining (red) colocalizes with the endothelial marker (green), and appears entirely confined within the capillary loops, indicating that the staining is truly in endothelial cells and not in podocytes or mesangial cells. The lower panels show two examples of a proximal tubule and neighboring peritubular capillary. Apical co-localization of the CLIC4 signal (red) with the brush border marker (blue) is again evident. Less intense punctate staining is present both in the cytoplasm and the nuclei of the proximal tubule cells at about the same intensity. Peritubular capillary endothelia stain throughout with the CLIC4 antibody (red), colocalizing with IB4 (green), and there is punctate staining of the endothelial cell nuclei.

\section{CLIC4 in growth and development}

We had previously reported that Clic4 null mice were underrepresented in the offspring from Clic4 heterozygous parents, and that adult Clic4 null male mice were smaller than littermate WT or Clic4 heterozygotes [13]. The lower weight among Clic4 null males was apparent by 5 weeks of age and persisted throughout life.

A cohort of age-matched 10-11 week old mice were used to assay whether the kidneys were smaller in the absence of CLIC4. Male and female mice of each genotype were studied as shown in Table 1. Both body and kidney mass of Clic4 null mice were smaller than those of WT mice in both sexes. Kidney-to-body mass ratio was significantly lower in the male mice but not different in the female mice.

\section{CLIC4 and renal angiogenesis}

Absence of CLIC4 has been previously shown to impair angiogenesis; CLIC4 has been implicated in the intracellular tubulogenesis of endothelial cells [17] and is present in both glomerular and peritubular endothelial cells in the kidney (shown above). Thus, it is plausible that Clic4 null mice may have impaired renal angiogenesis that could affect both kidney size and susceptibility to acute kidney injury. Decreased angiogenesis might be reflected in the total number of glomeruli and/or by decreased capillary density in the kidney.

Age-matched adult male WT and Clic4 null mice (7 of each genotype) were used to determine glomerular counts. Glomeruli were stained by post-mortem perfusion of the mice with Alcian Blue followed by maceration of the kidneys in hydrochloric acid and then counting blue-stained glomeruli in aliquots of the resulting suspension. Results are shown in Figure 4. WT mice were found to average $13,785 \pm 325$ glomeruli per kidney while Clic4 null mice had 12,142 \pm 531 glomeruli per

Table 1 Body and kidney mass of adult mice

\begin{tabular}{llll}
\hline & WT & C4 null & P value \\
\hline Males $\mathbf{n}$ & 10 & 9 & \\
Body mass (gm) & $45.6 \pm 1.3$ & $34.9 \pm 1.3$ & 0.00002 \\
Kidney mass (gm) & $0.776 \pm 0.031$ & $0.533 \pm 0.019$ & 0.000006 \\
Kidney/Body (\%) & $1.70 \pm 0.04$ & $1.53 \pm 0.03$ & 0.0023 \\
Females $\mathbf{n}$ & 10 & 10 & \\
Body mass (gm) & $35.9 \pm 1.3$ & $27.8 \pm 0.8$ & 0.00004 \\
Kidney mass (gm) & $0.446 \pm 0.016$ & $0.360 \pm 0.019$ & 0.0032 \\
Kidney/Body (\%) & $1.24 \pm 0.03$ & $1.30 \pm 0.06$ & NS \\
\hline
\end{tabular}



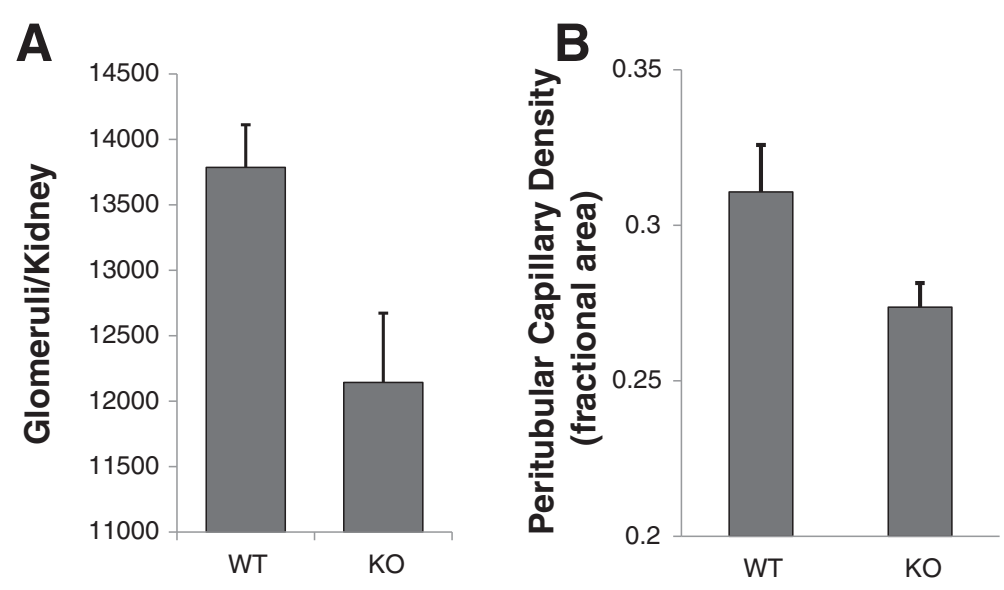

Figure 4 Glomerular count and peritubular capillary density of WT and Clic4 null mice. A. Glomeruli per kidney was determined by counting Alcian blue-stained glomeruli in aliquots of macerated kidney. WT: 13,785 $\pm 325(n=7)$ glomeruli per kidney; Clic4 null: $12,142 \pm 531$ ( $n=7)$ glomeruli per kidney $(\mathrm{P}=0.022)$. B. Fractional area of a central longitudinal section of kidney stained with the endothelial cell marker CD31. WT: $31.1 \pm$ $1.5 \%(n=8)$; Clic4 null: $27.4 \pm 0.8 \%(n=8)(P=0.047)$.

kidney $(\mathrm{P}=0.022)$. Thus the Clic4 null mice were found to have $12 \%$ fewer glomeruli than the WT mice.

Peritubular capillary density was determined by quantitative image analysis of fluorescently stained kidney sections. Eight WT and Clic4 null age-matched mice (4 male and 4 female of each genotype) were used in the experiment. Kidneys were harvested and longitudinal frozen sections through the center of each kidney were stained for CD31, a marker of endothelial cells. A series of contiguous images covering the entire length of the section from pole to pole was collected from each kidney. Representative images from the renal cortex are shown in Figure 5A and B. The fraction of the surface area of the kidney section stained with the endothelial cell marker, excluding glomeruli and large vessels, was determined. Results are shown in Figure 4B. $31.1 \pm 1.5 \%$ of the wild type kidney sections and $27.4 \pm 0.8 \%$ of the Clic4 null kidney sections consists of capillaries $(\mathrm{P}=$ 0.047). Female mice tended to have a less dense peritubular capillary network than males, but this difference did not reach the 95\% confidence level in either genotype.

\section{CLIC4 and proteinuria}

Mice were examined for the presence of proteinuria. Urine was collected from age-matched young adult male mice (6-10 weeks old) and the creatinine and protein concentrations determined. Results are presented in Figure 6A. Urine protein-to-creatinine ratios were 0.296 $\pm 0.030 \mathrm{mg} / \mathrm{mg}$ in WT $(\mathrm{n}=17)$ and $1.074 \pm 0.182 \mathrm{mg} / \mathrm{mg}$ in Clic4 null $(\mathrm{n}=17), \mathrm{P}=0.00019$. Thus Clic4 null mice have about 3.5 fold increased proteinuria compared to WT. To examine whether this represents glomerular or
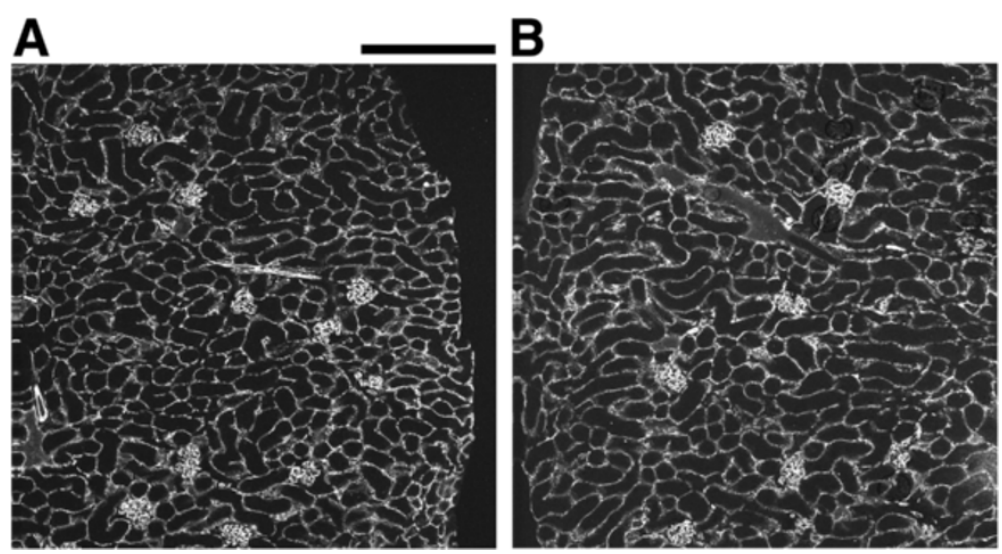

Figure 5 Representative images of CD31-stained kidney sections used to generate the peritubular capillary density data. The fraction of the kidney cross sectional area stained for CD31 was determined after excluding glomeruli and large vessel. A. Section from a WT kidney. B. Section from a Clic4 null kidney. Scale bar represents 200 microns. 

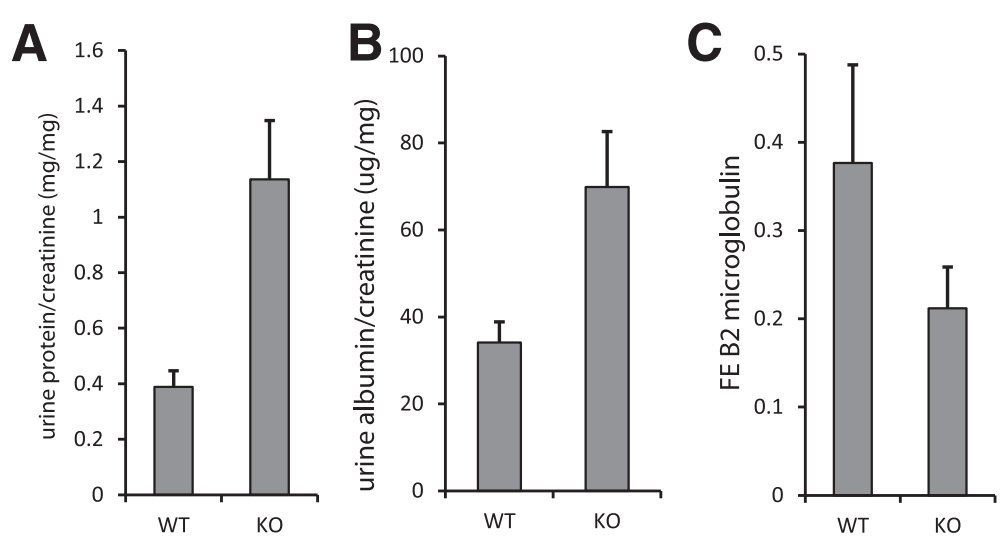

Figure 6 Proteinuria in Clic4 null mice. A. Total protein to creatinine ratio in urine from young adult male mice. WT: $0.296 \pm 0.030 \mathrm{mg} / \mathrm{mg}$ $(\mathrm{n}=17)$; Clic4 null: $1.074 \pm 0.182 \mathrm{mg} / \mathrm{mg}(\mathrm{n}=17), P=0.00019$. B. Urine albumin to creatinine ratio using a different set of male mice. WT: $34.1 \pm$ $10.7 \mu \mathrm{g} / \mathrm{mg}(n=5)$; Clic4 null $69.8 \pm 28.5 \mu \mathrm{g} / \mathrm{mg}(n=5)(P=0.030)$. C. Fractional excretion of $\beta 2$ microglobulin in the same mice used in panel $\mathbf{B}$. WT: $0.37 \% \pm 0.11(n=5)$ Clic4 null: $0.21 \% \pm .04(n=5)$ (n.s.).

tubular proteinuria, the urine albumin-to-creatinine ratio and the fractional excretion of $\beta 2$ microglobulin were determined among a different cohort of 5 age-matched male mice of each genotype (presented in Figure 6B and C). Urine albumin-to-creatinine ratios were $34.1 \pm 4.8 \mu \mathrm{g} / \mathrm{mg}$ for the WT mice and $69.8 \pm 12.8 \mu \mathrm{g} / \mathrm{mg}$ for the Clic4 null mice $(P=0.030)$. Fractional excretions of $\beta 2$ microglobulin were $0.37 \% \pm 0.11(\mathrm{n}=5)$ for the WT and $0.21 \% \pm 0.04$ $(\mathrm{n}=5)$ for the Clic4 null (n.s.). The albumin-to-creatinine ratio in the urine is significantly increased while fractional excretion of $\beta 2$ microglobulin is not significantly different.

Ultrastructure of glomeruli from matched 6 week old WT and Clic4 null mice was examined as shown in Figure 7. We could find no consistent differences between the WT and Clic4 null glomeruli. In particular, both podocytes and glomerular endothelial cells were indistinguishable with neither prominent foot process effacement nor systematic changes in endothelial fenestrae.

\section{Acute kidney injury}

A total of 46 Clic4 null mice of 6.5 to 11.5 weeks of age (23 male, 23 female), and 46 age- and sex-matched WT mice were subjected to folic acid injury using intraperitoneal injections of $30 \mathrm{mg} / \mathrm{ml}$ folic acid dissolved in $300 \mathrm{mM}$ sodium bicarbonate at a dose of $250 \mathrm{mg}$ folic acid per kg body weight in two separate experiments. Blood samples were taken before the experiment and at 2,7 , and 21 days for blood urea nitrogen (BUN) determination. Mice were sacrificed at 21 days at which time kidneys were weighed and processed for histology. Baseline characteristics of the mice are shown in Table 2. Baseline BUN concentrations were no different between the WT and Clic4 null mice and the two populations were well matched for sex, age, and weight.

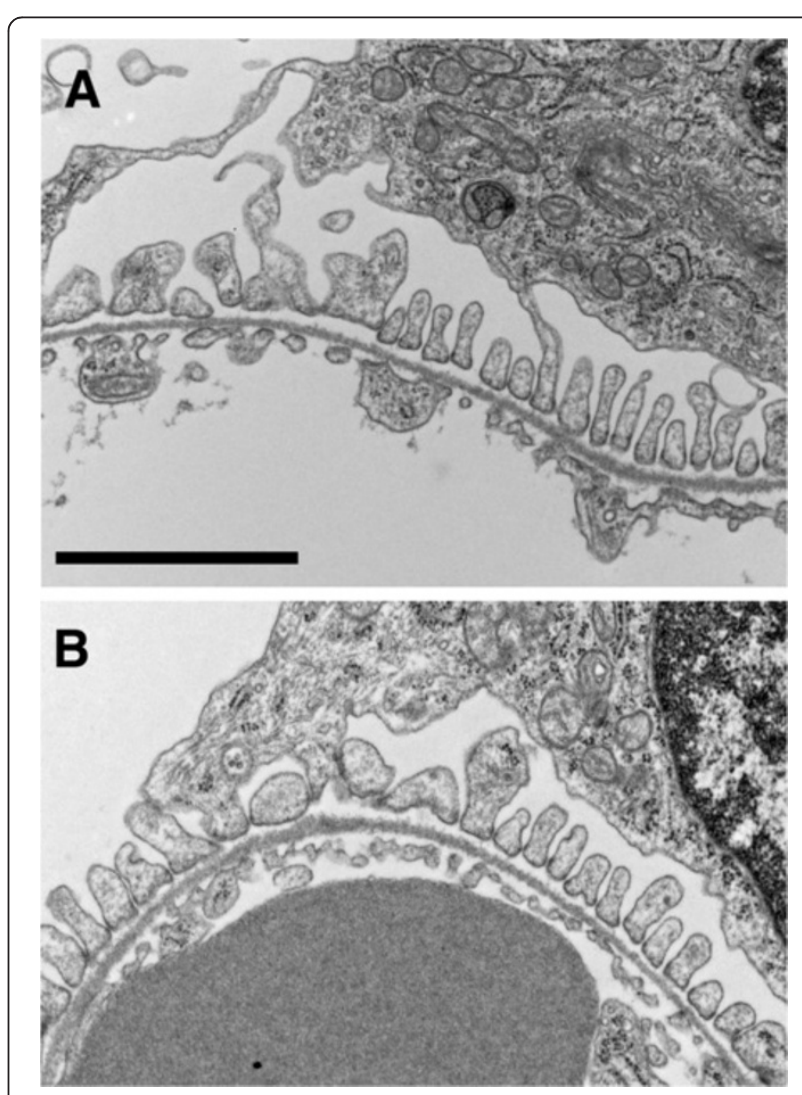

Figure 7 Electron micrographs of glomeruli from WT and Clic4 null mice. A. Wild type. B. Clic4 null. In each, a section of a glomerular capillary is shown with the blood space below and the urinary space above, separated by basement membrane. The urinary surface of the basement membrane is lined with well-formed podocyte foot processes. The blood surface is lined with fenestrated endothelium. Scale bar represents 2 microns. 
Table 2 AKI following folic acid injection

\begin{tabular}{|c|c|c|c|}
\hline & WT $(n=46)$ & KO $(n=46)$ & $P$ value \\
\hline Baseline BUN & $26.0 \pm 0.81$ & $26.3 \pm 1.13$ & NS \\
\hline Baseline age in weeks (mean, range) & $8.4,7-11.5$ & $8.3,6-11$ & NS \\
\hline Baseline weight in grams (mean, range) & $29.8,22.1-40.6$ & $29.6,22-39.5$ & NS \\
\hline Day 2 BUN & & & 0.021 \\
\hline Mean & 109 & 187 & \\
\hline Median & 65 & 143 & \\
\hline No. BUN $<50$ & $20(43 \%)$ & $11(24 \%)$ & 0.077 \\
\hline No. $B U N>200$ & $7(15 \%)$ & $20(43 \%)$ & 0.0055 \\
\hline No. dead with renal failure within 7 days & $1(2.2 \%)$ & $7(15 \%)$ & 0.059 \\
\hline
\end{tabular}

The day 2 BUN results are shown in Figure 8 and summarized in Table 2 . There is a marked heterogeneity in the degree of acute kidney injury in response to intraperitoneal folic acid within each population. Fully 43\% (20 out of 46) of the wild type mice and 24\% (11 out of 46) of the Clic4 null mice had minimal acute kidney injury with day two BUN less than $50 \mathrm{mg} / \mathrm{dl}$ (N.S., $\mathrm{P}=$ 0.077 ). Conversely, $13 \%$ of the WT mice and $43 \%$ of the

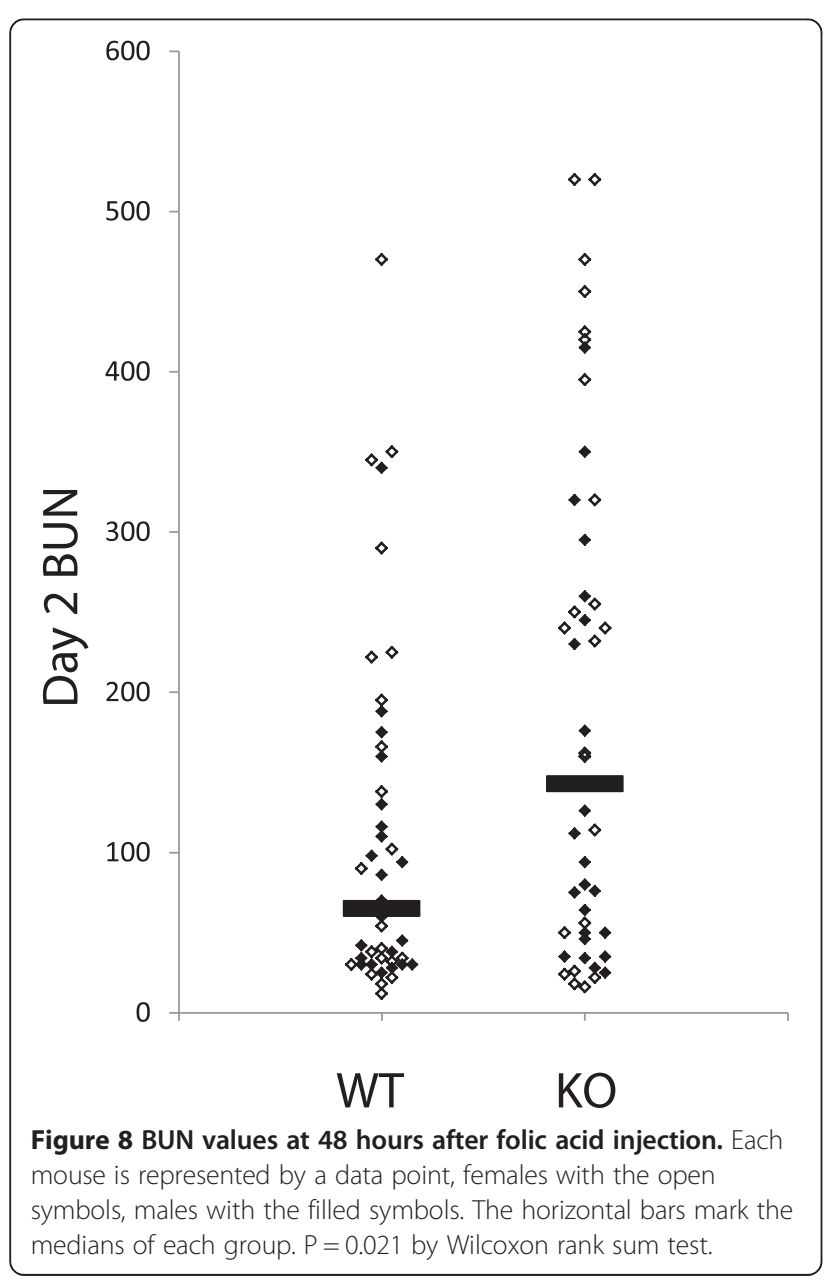

Clic4 null mice had severe kidney injury with the day two BUN values greater than $200 \mathrm{mg} / \mathrm{dl}(\mathrm{P}=0.0055)$. The mean 48 hour BUNs for the WT and Clic4 null mice are $109 \mathrm{mg} / \mathrm{dl}$ and $187 \mathrm{mg} / \mathrm{dl}$ and the medians are $65 \mathrm{mg} / \mathrm{dl}$ and $143 \mathrm{mg} / \mathrm{dl}$, respectively $(\mathrm{P}=0.021$ using Wilcoxon non-parametric testing). One WT mouse (2.2\%) and 7 Clic4 null mice (15.2\%) died with severe AKI within one week of folic acid injection $(\mathrm{P}=0.059)$. In sum, the Clic4 null mice are significantly more susceptible to folic acid-induced acute kidney injury with higher average and median blood urea at 48 hours after injection, and a significantly higher fraction with severe injury. In addition the Clic4 null mice show a trend toward fewer mice with minimal injury and more mice dying of acute injury within one week of folic acid injection, although these do not reach the 95\% confidence level.

In both WT and Clic4 null mice, the females tended to have more severe acute injury than the males as reflected in the day 2 BUN but this trend did not approach the $95 \%$ confidence level in either genotype using Wilcoxon non-parametric testing.

\section{Distribution of CLIC4 following tubular injury}

Vibratome sections from wild type mouse kidney two days after folic acid exposure stained for CLIC4 (red), the proximal tubule marker LTA (green) and the nuclear marker DAPI (cyan) are shown in Figure 9. Lower magnification images are shown in the upper panel. The presence of significant tubular injury is reflected in these images as dilated tubules and loss of brush border. Other fields not presented here showed additional typical features of acute tubular injury including presence of sloughed cells in the tubule lumen and some areas where basement membrane appears to be devoid of epithelial cell covering. With loss of the brush border, LTA staining of is less prominent but enough residual staining remains to easily identify the proximal tubule as opposed to unstained distal tubules (indicated d). CLIC4 expression is still prominent in the injured proximal 

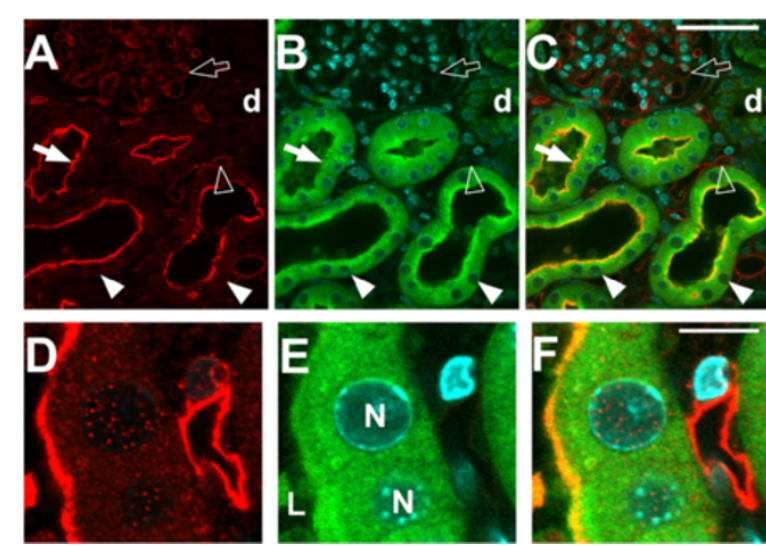

Figure 9 Immunolocalization of CLIC4 in WT mice $\mathbf{4 8}$ hours after folic acid induced acute kidney injury. Vibratome sections stained with affinity-purified antibody to CLIC4 (red) plus markers for proximal tubule brush border (Lectin LTA, blue) and nuclei (DAPI, cyan). A set of lower magnification image is shown in the upper set $(\mathbf{A}-\mathbf{C})$ and a higher magnification set from the same kidney in the lower set (D-F). A and D (left column): CLIC4 signal (red) alone; $\mathbf{B}$ and $\mathbf{E}$ (center column): merged image of brush border (green) and nuclear (cyan) markers; $\mathbf{C}$ and $\mathbf{F}$ (right column): merged image of the CLIC4 signal with markers. In the upper set, solid arrow: CLIC4 is tightly polarized to the apical membrane of the dilated proximal tubule which has lost its brush border; solid arrowhead: nuclear localization of CLIC4 is less prominent than in uninjured kidney; open arrow: CLIC4 in a glomerular capillary loop; open arrowhead: CLIC4 in a peritubular capillary. In the lower set, $L$ designates the lumen of the proximal tubule and $\mathrm{N}$ labels proximal tubule cell nuclei. A pertiubular capillary is present to the right.

tubule segments and the apical polarization of distribution is even more marked, with the majority of CLIC4 appearing to reside in or immediately beneath the apical plasma membrane (solid arrow). In contrast to the uninjured kidney, CLIC4 is easily detected throughout the proximal tubule including the more distal straight segments (not demonstrated). Whether this represents upregulation of CLIC4 in these cells, or more pronounced polarization of distribution is not clear. Contrary to predictions of our initial hypothesis, the modest nuclear staining in proximal tubule cells noted in the un-injured kidney (see Figures 2 and 3) has not dramatically changed, and is certainly not more prominent. Endothelial staining for CLIC4 in both peritubular (open arrowhead) and glomerular (open arrow) capillaries appears to be unchanged following injury. The lower panel shows higher magnification images including a segment of proximal tubule epithelium with underlying peritubular capillary, demonstrating persistent punctate nuclear staining which is not significantly different from that seen in uninjured kidney.

\section{Recovery from acute injury}

Since the degree of injury is so heterogeneous, assessment of the recovery from injury is not straightforward.
To analyze functional recovery, we first looked at the BUN at 21 days as a function of the BUN at day 2. Data for all the mice that survived to 21 days is plotted in Figure 10A. As expected, mice with greater initial injury had higher BUN at 21 days, although all the mice showed very significant functional recovery with none of the mice having a 21 day BUN greater than $60 \mathrm{mg} / \mathrm{dl}$. The slopes of the linear regression lines derived from these data are $0.069 \pm 0.015$ for the WT and $0.054 \pm$ 0.009 for the Clic4 nulls, which are not significantly different, indicating that there is no significant difference between these populations in the extent of renal recovery as a function of the severity of initial injury.

To examine recovery in a different way, we limited our analysis to animals which suffered severe injury with a BUN of $200 \mathrm{mg} / \mathrm{dl}$ or greater on day 2 and who survived to day 21 . Five WT mice and 13 Clic4 null mice met these criteria. Average BUN values on days 2, 7, and 21 are plotted in Figure 10B. Both WT and Clic4 null mice which survived severe initial injury showed good recovery of kidney function and the BUN values did not differ between the two groups at any time point. Thus extent and rate of functional recovery as reflected by BUN was not different between the WT and Clic4 null mice.

At 21 days after injury, mice were euthanized and kidneys harvested. After weighing, kidneys were fixed. Longitudinal sections were obtained through the center of the kidney and stained with Mason's Trichrome to assess extent of fibrosis. Typical interstitial fibrosis was found that correlated with the degree of initial injury - mice with minimal initial rise in BUN showed minimal scarring while mice with markedly elevate day 2 BUNs had more significant fibrotic scars. Representative images of WT and Clic4 null kidneys harvested 3 weeks after severe injury are shown in Figure 11. The fraction of the cross sectional area that was occupied by fibrosis was determined for a subset of the mice (23 WT and 22 CLIC4 nulls). The median fractional fibrosis was $6.85 \%$ and $10.37 \%$ for the WT and CLIC4 null mice, respectively, which did not reach statistical significance using Wilcoxon non-parametric testing. However, the marked difference in susceptibility to initial injury rendered this observation difficult to interpret. As with the functional recovery discussed above, we analyzed the degree of chronic fibrosis as a function of the initial injury to determine whether there may be a difference in fibrosis. Fractional fibrosis plotted against the day $2 \mathrm{BUN}$ is shown in Figure 12A. As expected, there is a strong correlation of extent of fibrosis with the degree of initial injury. The slope of the regression lines are $0.00104 \pm$ 0.0001 and $0.000801 \pm 0.00014$ for the WT and Clic4 null mice, respectively, with the difference not approaching significance at the $95 \%$ confidence level. 


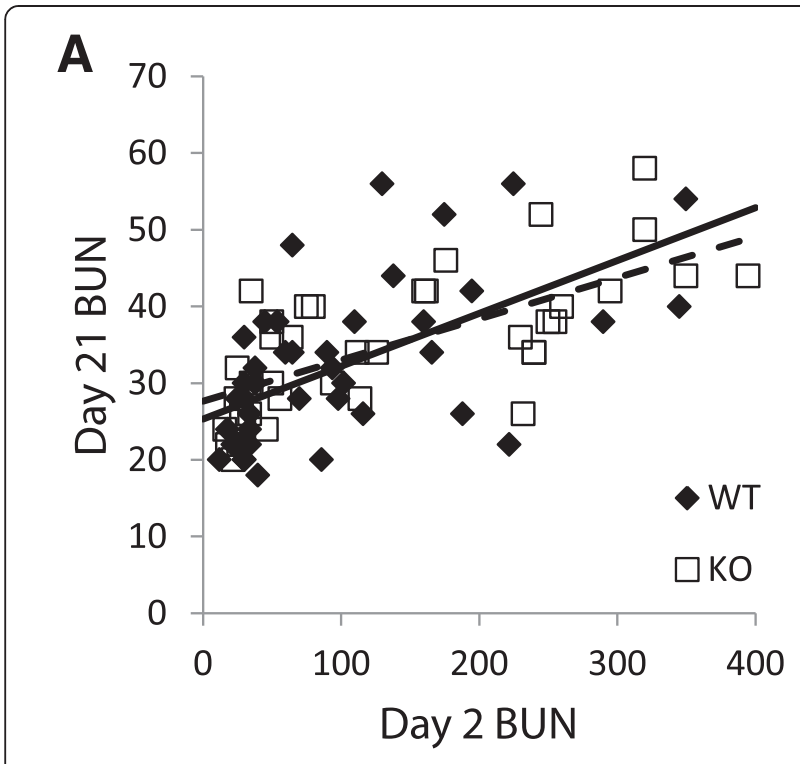

B

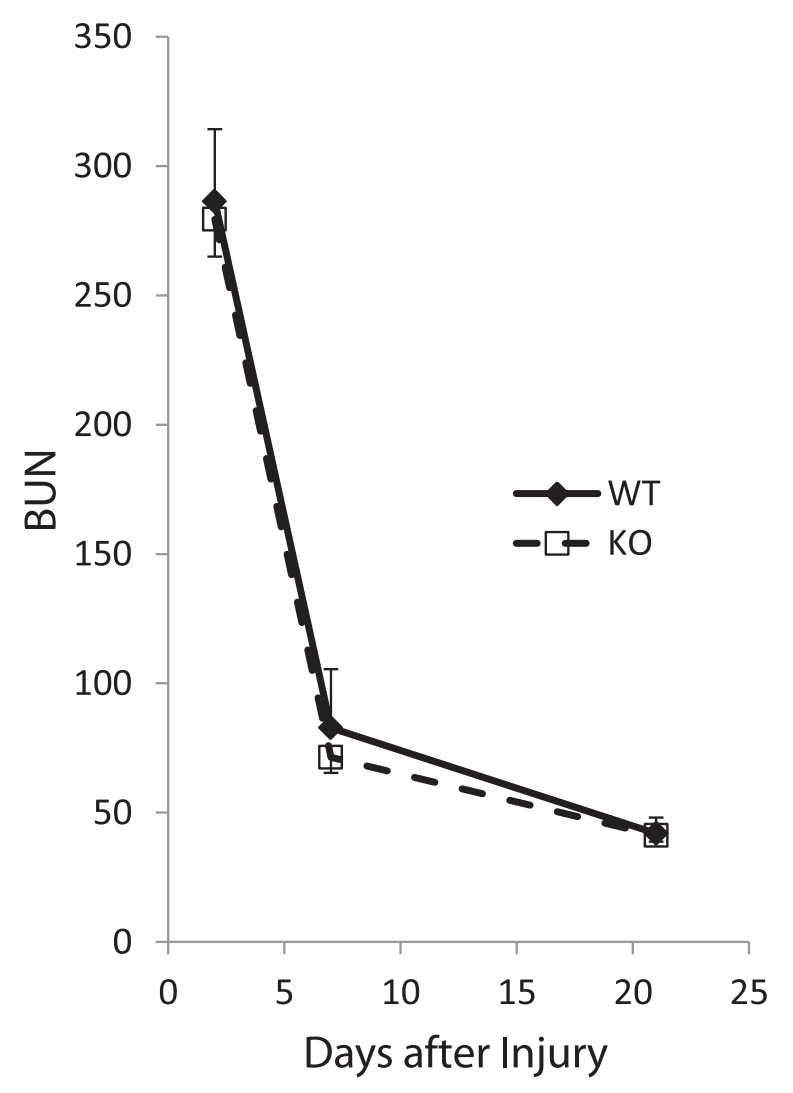

Figure 10 Functional recovery following acute kidney injury. A.

The BUN values at day 21 are plotted as a function of the BUN at day 2 for each mouse. Solid line represents linear regression for data from WT mice; dashed line for Clic4 null mice. The slopes of the lines are: WT $0.069 \pm 0.015 ; \mathrm{KO} 0.054 \pm 0.009$ (NS). B. Average BUN values for all mice with day 2 BUNs greater than 100 who survived to day 21. Standard errors are shown in only one direction to improve legibility. There is no significant difference between the average values at any time point.

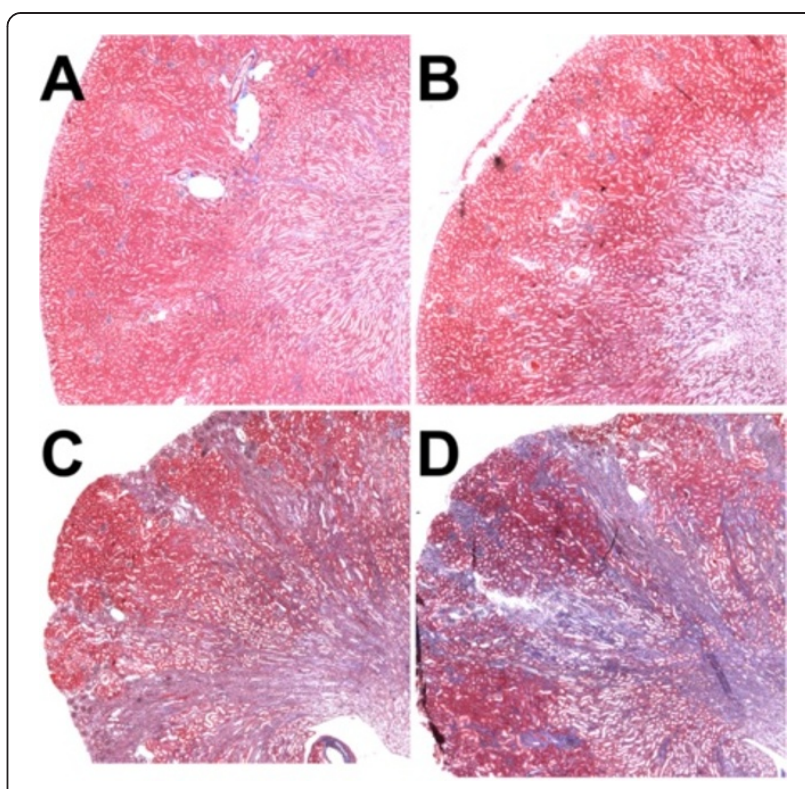

Figure 11 Chronic scarring following acute kidney injury. Central longitudinal kidney sections were prepared at 21 days after folic acid injury and stained with Mason's Trichrome, which stains collagen blue. The upper panels show representative kidneys of mice sustaining minor injury and the lower panels are from mice sustaining severe injury; WT mice on the left, Clic4 null mice on the right of each pair. A. WT mouse with day 2 BUN of $30 \mathrm{mg} / \mathrm{dl}$, day 21 BUN $20 \mathrm{mg} / \mathrm{dl}$, and section scored at 2.8\% fibrosis. B. Clic4 null mouse with day 2 BUN of $34 \mathrm{mg} / \mathrm{dl}$, day $21 \mathrm{BUN} 26 \mathrm{mg} / \mathrm{dl}$, and section scored at $2.1 \%$ fibrosis. C. WT mouse with day 2 BUN of $350 \mathrm{mg} / \mathrm{dl}$, day $21 \mathrm{BUN} 54 \mathrm{mg} / \mathrm{dl}$, and section scored at 38\% fibrosis. D. Clic4 null mouse with day 2 BUN of $395 \mathrm{mg} / \mathrm{dl}$, day 21 BUN $44 \mathrm{mg} / \mathrm{dl}$, and section scored at $32 \%$ fibrosis.

Long-term renal scarring and fibrosis results in loss of renal mass, which is more easily and unambiguously quantified than are histologic scarring indices. To ask indirectly whether the absence of Clic4 affects post-AKI scarring, we analyzed the relationship between the extent of initial injury and renal mass at 21 days after injury.

Our analysis was initially limited by the low number of WT mice that suffered severe injury. In order to increase the population with severe initial injury, we attempted to increase the intensity of the toxic exposure. In pilot experiments, we found that simply increasing the amount of folic acid solution at the same concentration had little effect on extent of kidney injury. Even doubling the dose did not appreciably change the fraction of mice suffering severe injury. In contrast, using the same dose of folic acid, but administering it in a more concentrated solution greatly increased toxicity.

We injected 29 WT mice (14 females, 15 males) and 31 Clic4 null mice (15 females, 16 males) from the same population that was used for the large scale experiments described previously. The female mice received $250 \mathrm{mg} / \mathrm{kg}$ folic acid at $40 \mathrm{mg} / \mathrm{ml}$ in $300 \mathrm{mM}$ sodium bicarbonate, 


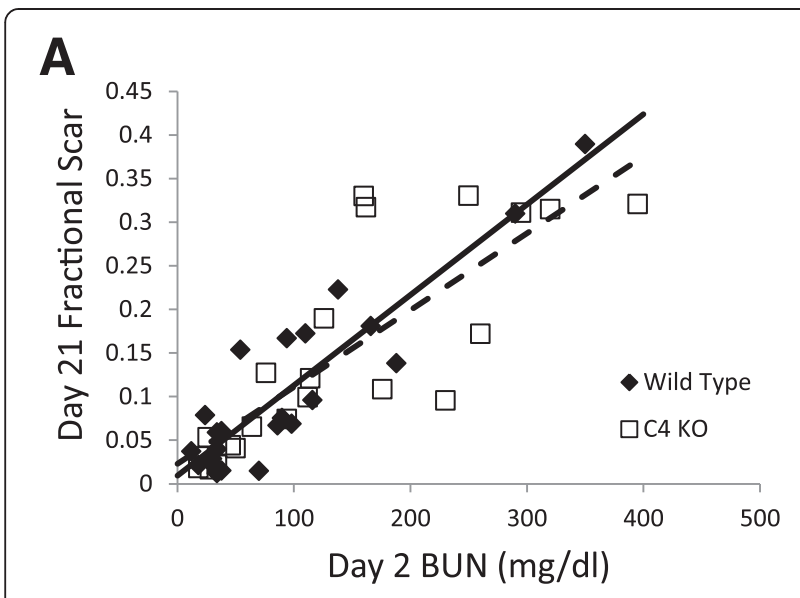

B

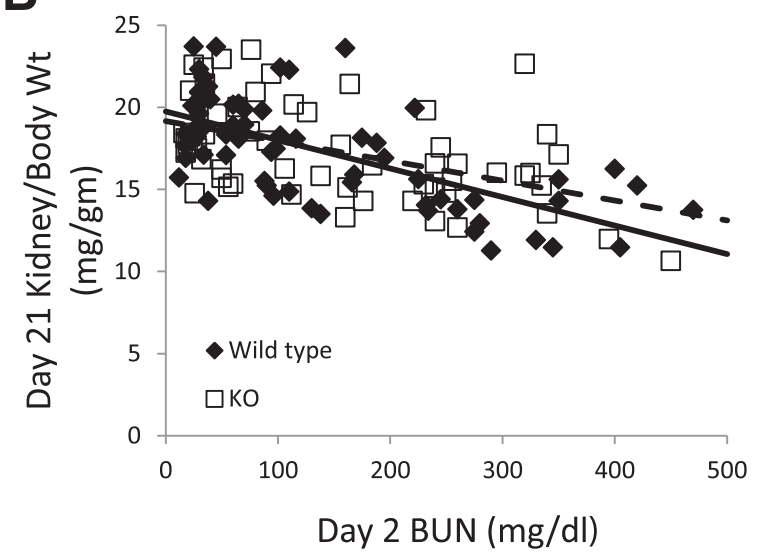

Figure 12 Quantification of chronic scarring following acute injury. A. Fractional area of a central longitudinal kidney section stained blue by Mason's trichrome is plotted as a function of the day 2 BUN. B. Ratio of day 21 total kidney mass to pre-injury body mass is plotted as a function of the day 2 BUN for each mouse. In both panels A and B, WT mice are represented by filled diamonds, Clic4 null mice by open squares. Solid line represents linear regression line for the WT, dashed line represents the linear regression line for the Clic4 null. See text for values and standard error of the slopes. The slopes of the linear regression lines are not different between the WT and Clic4 null mice in either graph.

and the male mice received $250 \mathrm{mg} / \mathrm{kg}$ folic acid at $50 \mathrm{mg} / \mathrm{ml}$ in $300 \mathrm{mM}$ sodium bicarbonate. The baseline characteristics of these mice were as follows: WT average age 9.3 weeks (range 6-15.5), average weight $28.9 \mathrm{gm}$ (range 21.1-39.9); Clic4 null average age 10.0 weeks (range 7 - 15.1), average weight 30.7 (range 21.8-38.5). These mice suffered much more significant initial injury on average than the initial cohort given the same dose at $30 \mathrm{mg} / \mathrm{ml} .56 \%$ of the wild type mice and $65 \%$ of the Clic4 null mice had day 2 day BUN values greater than $100 \mathrm{mg} /$ $\mathrm{dl}$ (NS). The differences do not reach the $95 \%$ confidence level although the mean and median day 2 BUNs showed a trend toward more severe injury among the Clic4 nulls (WT and $\mathrm{KO}$ means $249 \mathrm{mg} / \mathrm{dl}$ and $271 \mathrm{mg} / \mathrm{dl}$; medians
$260 \mathrm{mg} / \mathrm{dl}$ and $325 \mathrm{mg} / \mathrm{dl}$, respectively). Twenty-three of the $29 \mathrm{WT}$ and 20 of the 32 Clic4 null mice survived to 21 days at which time the mice were sacrificed and kidneys harvested.

Final (day 21) kidney weight was normalized to mouse body weight on day 0 and plotted as a function of the BUN on day 2 following folic acid injection. For this analysis only, data were pooled from the entire population treated with folic acid from both dosing protocols that survived to day 21 (67 WT and $58 \mathrm{KO}$ mice). Results are shown in Figure 12B. There is a noticeable relationship between initial injury and the kidney weight following recovery with more severely injured kidneys undergoing more significant loss of mass. Linear regression lines from the data are shown and have slopes of $-0.0174 \pm 0.0024$ and $-0.0121 \pm 0.0028$ for the WT and Clic4 null, respectively, with the difference not approaching significance at the $95 \%$ confidence level. Thus the degree of scarring as reflected in chronic loss of renal mass for a given amount of acute injury is not significantly different between the WT and Clic4 null mice.

\section{Molecular markers of response to acute injury}

To look more directly for an effect of CLIC4 on TGF $\beta$ signaling following acute kidney injury, we assessed phosphorylation of the SMAD pathway. One of the proximal steps in intracellular TGF $\beta$ signal transduction is the phosphorylation of SMADs 2 and 3. In keratinocytes, it has been demonstrated that CLIC4, through interactions with the protein Schnurri, potentiates TGF $\beta$ signaling by increasing the half-life of phosphorylated SMADs 2 and 3. If this also occurs during TGF $\beta$ signaling following acute kidney injury, we would expect to find lower levels of phosphorylated SMADs 2 and 3 in the injured Clic4 null mice than in injured WT mice.

A cohort of 48 age and sex-matched WT and Clic4 null mice (12 males and 12 females in each group) were treated with the more toxic folic acid protocol noted above, $(250 \mathrm{mg} / \mathrm{kg}$ folic acid at $50 \mathrm{mg} / \mathrm{ml}$ in $300 \mathrm{mM}$ sodium bicarbonate given as an intraperitoneal injection) expected to cause severe injury in most mice. Baseline characteristics of the mice were as follows: WT mice, average age 8.4 weeks (range 7.6 - 9.7), average weight 32.4 gm (range 23.7 - 40.4); Clic4 null mice, average age 8.6 weeks (range $6.1-10.1$ ), average weight 31.8 (range $23.7-42.8)$. One third of the mice were sacrificed prior to injury, one third at 24 hours after injury, and one third at 48 hours after injury. Equal numbers of males and females were sacrificed at each time point. One female mouse of each genotype intended for the 48 hour time point died and was not included in the analysis. Kidneys were harvested and total protein prepared. Fifty micrograms of protein were separated by SDS-PAGE, blotted, and sequentially probed for total SMAD 2-3 
(T-SMAD), phosphorylated SMAD 2-3 (P-SMAD), and GAPDH. Representative western blots are shown in Figure 13. In the T-SMAD and P-SMAD panels, SMAD 2 is the upper band and SMAD 3 is the lower band. The signals were normalized to the GAPDH signal as a loading control. Results for the entire data set are presented in Figure 14.

There was no significant difference in the level of total SMAD2 or 3 between the WT and Clic4 null mice (Figure 14B). Total amount of both SMADs tended to increase in response to injury but this increase only reached the $95 \%$ confidence level at 48 hour time point for SMAD3 in the Clic4 null mice. The levels of phosphorylated SMADs 2 and 3 normalized to GAPDH are shown in Figure 14A. The levels of both phosphorylated SMADs increased significantly over the 48 hours following injury. P-SMAD2 was more abundant than P-SMAD3 under all conditions. There appears to be a trend towards lower levels of P-SMAD2 in the Clic4 null mice compared to wild type mice, but this difference did not approach the $95 \%$ confidence level at any time point.

To consider the data in a different way, the P-SMAD signals were normalized to the total SMAD (T-SMAD) signals and re-analyzed as shown in Figure 14C. The PSMAD/T-SMAD ratio increased significantly by 48 hours after injury for SMAD2 and SMAD3 in both WT and Clic4 null mice. There is a trend to lower P-SMAD2/

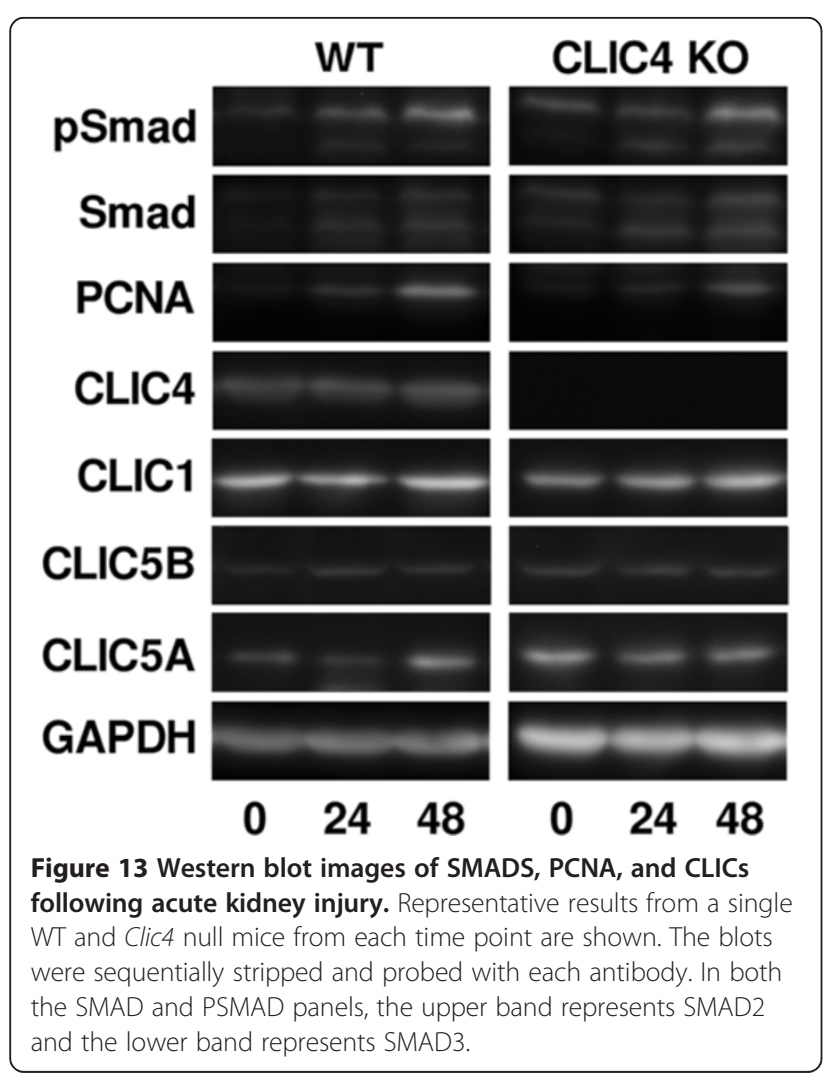

T-SMAD2 ratio in the CLIC4 null mice compared to the WT mice, but this trend does not reach the $95 \%$ confidence level at any time point.

In addition to TGF $\beta$ signaling, CLIC proteins have been implicated in cellular proliferation, a process which also figures prominently in the response to acute kidney injury. To assess proliferation, we quantified expression of proliferating cell nuclear antigen (PCNA) in kidney homogenates, using western blotting as above. PCNA signals normalized to GAPDH are plotted in Figure 14D. PCNA significantly increases in kidney at 48 hours after injury but there is no significant difference in PCNA levels between WT and Clic4 null mice.

\section{Expression of CLICs at baseline and following acute kidney injury}

The CLIC family of proteins is very highly conserved (reviewed in [8]). It is possible that compensation between CLICs may account for some of the relative lack of effect of absence of CLIC4 on kidney function and response to injury. The same western blots used to probe for expression of SMADs and PCNA above were stripped and sequentially probed with antibodies to CLICs 1, 4, and 5 which are known to be expressed in the kidney [32,40-43]. The results are shown in Figure 15. As expected, CLIC4 (Figure 15A) is detected in the wild type mice and absent from the Clic4 null mice at all time points. The level of expression of CLIC4 in the WT mice does not change in response to injury.

CLIC1 (Figure 15B) is present at comparable amounts in whole kidney lysates from uninjured WT and Clic4 null mice. Following injury of the WT mice, CLIC1 expression rises and is significantly higher at 48 hours than prior to injury. However, in the Clic4 null mice, CLIC1 expression did not change significantly in response to injury and at 48 hours after injury, expression of CLIC1 is significantly higher in the WT than in the Clic4 null mice.

CLIC5 is expressed in two different splice forms leading to two different proteins: a smaller gene product named CLIC5A, which very similar to CLIC1 and CLIC4, and larger gene product named CLIC5B containing an additional unique $\mathrm{N}$-terminal region that includes an $\mathrm{SH} 2$ domain binding site that, when tyrosine phosphorylated, interacts with Src family kinases [44]. CLIC5A is known to be expressed in glomerular podocytes $[42,43]$. The distribution of expression of CLIC5B in kidney has not been reported. CLIC5A and CLIC5B (Figure 15C) are present in amounts that are not significantly different in whole kidney homogenates of WT and Clic4 null mice at baseline. The levels of expression of both forms of CLIC5 do not change significantly in response to injury in the WT mice. However, in the Clic4 null mice, the drop in expression of CLIC5A 

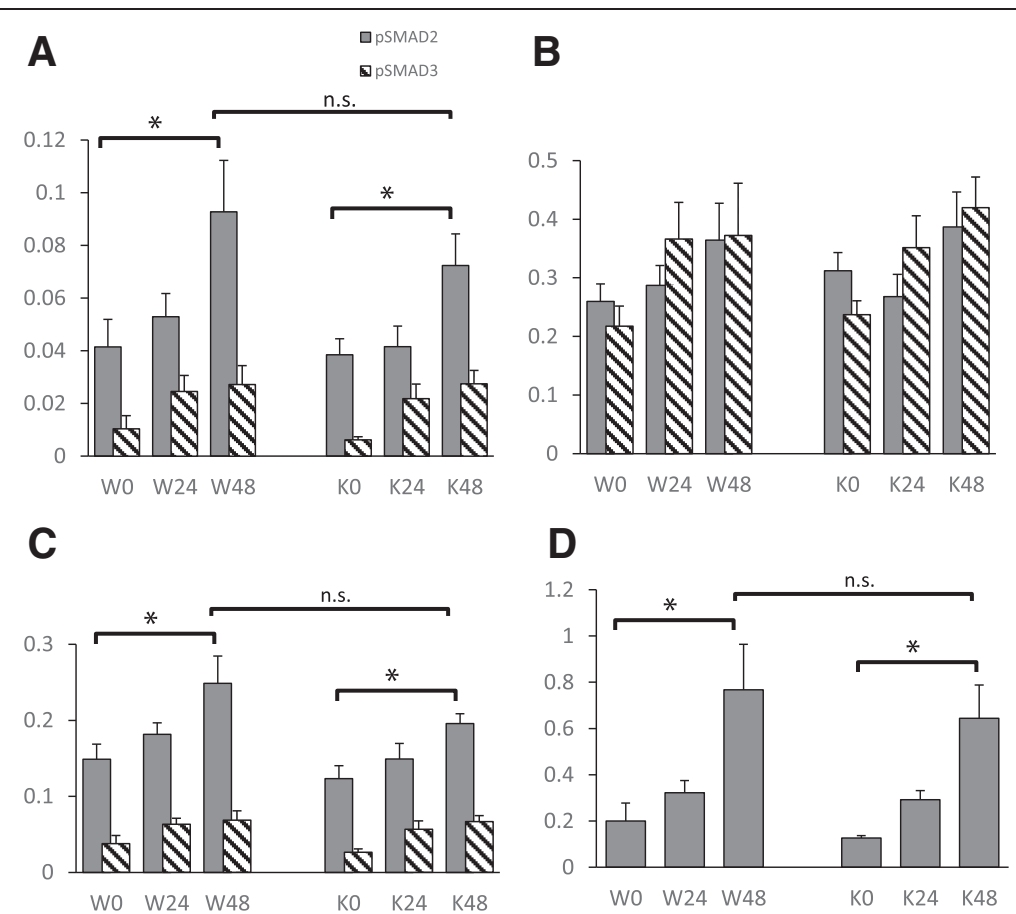

Figure 14 Quantification of western blot signals for SMADs and PCNA. Digitized chemiluminescent signals as in Figure 13 were normalized to the GAPDH signal from the same lane and plotted as arbitrary units. Values from wild type (W) and Clic4 null (K) mice are shown at 0, 24, and 48 hours after folic acid injury as indicated. $N=8$ for each group except for both 48 hour groups for which $n=7$ (one mouse from each group was lost prior to analysis). A. pSMADs 2 and 3 normalized to GAPDH. B. Total SMADs 2 and 3 normalized to GAPDH. C. pSMADs 2 and 3 normalized to total SMADS 2 and 3. In panels A-C, the SMAD2 signal is shown with the solid bars, the SMAD3 signal with the hatched bars. D. PCNA. Error bars indicate SEM. Asterisk indicates comparison with $P<0.05$. ns indicates not significant $(P>0.05)$.

following injury is much more prominent and the decline in level by 48 hours does reach the $95 \%$ confidence level. There is no significant difference in the CLIC5A or CLIC5B signals between WT and Clic4 null mice at any timepoint.

\section{Summary of AKI experiments}

The acute kidney injury experiments yielded two salient results: Clic4 null mice are more susceptible to folic acid induced acute kidney injury, and the absence of CLIC4 has no apparent impact on recovery from acute injury, either in function or in extent of scarring measured histologically or as reflected in kidney mass. Furthermore, we did not find any significant differences in SMAD phosphorylation or PCNA expression between WT and Clic4 null mice in response to acute injury, and injury itself did not affect the steady state level of CLIC4 protein in WT mice. There is no over-expression of CLIC1 or CLIC5 at baseline or following injury that would suggest compensation for the absence of CLIC4.

\section{Discussion}

The primary findings of this study are that the absence of CLIC4 results in smaller kidneys with fewer glomeruli and less dense peritubular capillary network, increased proteinuria that is primarily albumin with no increase in 及-2 microglobulinuria, and increased susceptibility to the acute kidney injury induced by folic acid with no difference in the functional or histologic recovery from acute injury.

\section{CLIC4 and susceptibility to acute injury}

Clic4 null mice were found to have differences in kidney structure that could contribute to increased susceptibility to acute injury. Clic4 null mice of both sexes have significantly smaller body mass and smaller kidneys than do WT mice. Furthermore, male Clic4 nulls have lower kidney to body mass ratio than do matched WT males. Thus, small kidney size may contribute to sensitivity to acute injury, even though baseline kidney function as estimated by steady state BUN levels is equivalent.

Small kidneys may be small because they have fewer glomeruli and nephrons, and reduced nephron number has been previously implicated as a risk factor for acute kidney injury. The recognized role of CLIC4 in angiogenesis suggests a mechanism by which Clic4 null mice may have fewer glomeruli. During development, glomerulogenesis is thought to require coordinated interaction between the renal corpuscle developing from the epithelial compartment, and invading endothelial cells providing the 


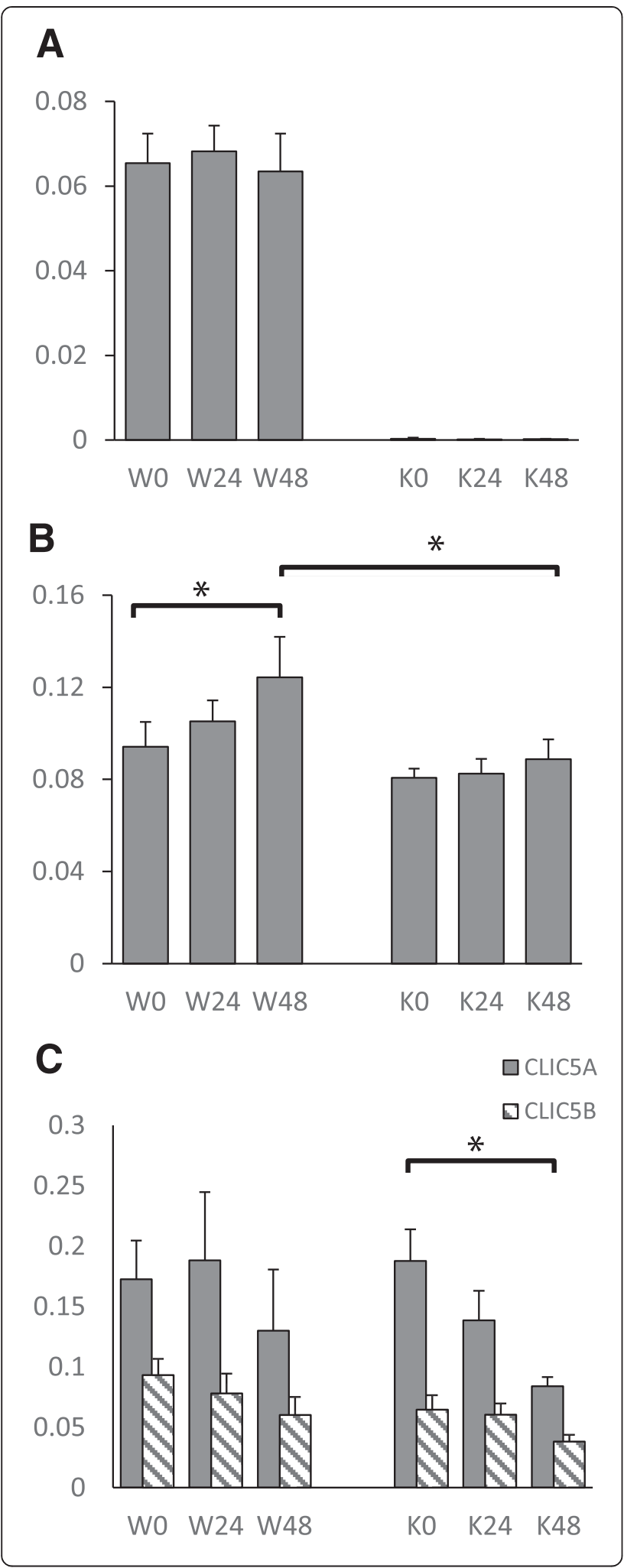

Figure 15 Quantification of western blot signals for CLICs 1, 4, and 5. Digitized chemiluminescent signals for the CLICs were normalized to the GAPDH signal in the same sample and plotted as arbitrary units. Values from wild type (W) and Clic4 null (K) mice are shown at 0,24 , and 48 hours after folic acid injury as indicated. $\mathrm{N}=8$ for each group except for both 48 hour groups for which $\mathrm{n}=7$ (one mouse from each group was lost prior to analysis). A. CLIC4. B. CLIC1. C. CLIC5 A and B. CLIC5A is shown with the solid bars, CLIC5B with the hatched bars. Error bars indicate SEM. Asterisk indicates comparison with $\mathrm{P}<0.05$.

vascular components. Failure or delay in endothelial invasion of the renal corpuscle could decrease the number of fully developed glomeruli. With this in mind, we determined the number of glomeruli in WT and matched Clic4 null mice and found that the absence of CLIC4 is associated with a $12 \%$ decline in glomerular number in adults.

Impaired angiogenesis during development might also result in a less dense peritubular capillary network which may be a risk factor for susceptibility to acute kidney injury, and indeed we found that the absence of CLIC4 is associated with a $12 \%$ decrease in the fraction of longitudinal kidney sections that are occupied by peritubular capillaries. Absence of CLIC4 could potentially also effect the active angiogenic response to acute kidney injury [45]. Increased angiogenesis in the peritubular capillaries following acute folic acid nephrotoxicity in mice has been reported. This angiogenesis may be at least partially driven by changes in levels of angiopoeitin 1 , vascular-endothelial growth factor $\mathrm{A}$, and hypoxia inducible factor $1 \alpha$ which occur in the same time frame $[6,45]$. Whether this response has an impact on the severity of the acute injury itself or only on the chronic consequences of acute injury is uncertain.

\section{CLIC4 and proteinuria}

Proteinuria has clearly been associated with increased risk of acute kidney injury both in human studies and in animal models [46]. We found that the urine proteinto-creatinine ratio of Clic4 null mice was elevated more than 3 fold. Since CLIC4 is prominently expressed in both glomeruli and proximal tubules, it is conceivable that absence of CLIC4 could result in proteinuria induced by either glomerular dysfunction, tubular dysfunction, or both. To differentiate these two, we separately assessed albuminuria and $\beta 2$ microglobulinuria. One would expect urinary albumin to be increased during proteinuria of either glomerular or tubular origin, while $\beta 2$ microglobulinuria would only be increased during tubular proteinuria. We found that albuminuria as reflected by the urine albumin to creatinine ratio was significantly elevated among the Clic4 null mice, while the fractional excretion of $\beta 2$ microglobulin was unchanged. We conclude that Clic4 null mice have proteinuria of glomerular origin, presumably a result of 
alterations in the glomerular capillaries as a consequence of the absence of CLIC4 from these cells. However, ultrastructural analysis failed to demonstrate the typical morphologic alterations in the structure of either the glomerular endothelial cells or podocytes that could explain the proteinuria.

There are some limitations to the conclusions regarding proteinuria that should be noted. First, the estimations of proteinuria in this study were entirely based on the ratio of protein to creatinine in the urine, not 24 hour urine collections. The inherent assumption is that steady state rates of creatinine production are similar between WT and Clic4 null mice, an assumption that was not tested. Second, rather than increased glomerular albumin leakage, an alternative explanation for selective albuminuria without $\beta 2$ microglobulinuria could be a selective defect in proximal tubule endocytosis that effects only the albumin endocytic pathway but the the $\beta 2$ microglobulin pathway. Finally, low glomerular number itself has been associated with albuminuria in mice although a causal relationship is uncertain [47]. Thus it is possible that the modest proteinuria seen in the Clic4 null mice could be a consequence of the low glomerular number resulting from the absence of CLIC4 during development, and not an independent effect of absence of CLIC4 in the adult kidney.

\section{Folic acid model of acute kidney injury}

We chose the folic acid model of acute injury because it uses a relatively non-toxic agent, is easy to administer to a large number of animals, and has been used with success in prior studies of acute kidney injury and subsequent fibrosis [37]. However, we found this model to possess some significant shortcomings. The marked variability in the extent of kidney injury to a fixed dose of folic acid rendered the data difficult to interpret. The degree of acute kidney injury as reflected by BUNs does not follow a Gaussian distribution. None-the-less, nonparametric statistical methods demonstrated a significant difference in the severity of acute injury as reflected in the 48 hour BUN values. Additional criteria suggest that the severity of injury is different between the two populations: the fraction of mice suffering severe acute injury is significantly different, and there are trends that do not quite reach the $95 \%$ confidence level that the fraction of mice suffering minimal injury is lower, and the fraction of mice dying with severe AKI within 7 days of injury are higher in the Clic4 null population than in the WT. Therefore, the observation that Clic4 null mice are more susceptible to folic acid-induced acute injury is strongly supported by the data. Factors contributing to the enhanced susceptibility to AKI are uncertain, but low glomerular/nephron number, low peritubular capillary density, and proteinuria have all been shown or suggested to increase risk of AKI in the past $[46,48,49]$.

\section{CLIC4 and TGF $\beta$ signalling following acute kidney injury}

The differences in initial injury between the populations, complicated by the marked variability of extent of injury within each population, made it very difficult to compare recovery and fibrosis between the WT and Clic4 null populations. We used two methods of analysis to assess functional recovery while compensating for degree of initial injury. First, we looked at the extent of long term functional recovery as a function of initial injury and found no difference in this relationship between the WT and Clic4 null mice. Second, limiting the analysis to those mice which suffered severe initial injury with day 2 BUNs greater than 200, we found no difference in the rate or extent of recovery of kidney function between WT and Clic4 null mice.

Despite good functional recovery, histologic examination of kidneys 21 days after injury revealed extensive interstitial fibrosis in those mice that suffered severe initial injury. The fraction of the area of a longitudinal section that consisted of scar was determined. As expected, the extent of scarring correlated strongly with the degree of initial injury. However, there was no difference in the extent of chronic scarring as a function of the severity of the acute injury between the WT and Clic4 null mice. Furthermore, using a larger population of mice with an increased number suffering severe injury, there no difference in the 21 day kidney-to-body-weight ratio (a surrogate marker of extent of scarring) as a function of severity of initial injury between the WT and Clic4 nulls. Molecular analysis of the TGF $\beta$ signaling pathway failed to demonstrate a statistically significant difference in phosphorylation of SMADs 2 or 3 between WT and Clic4 null mice following injury, and immunolocalization of CLIC4 in injured kidney tubules failed to show nuclear redistribution of the protein. Taken together, the data do not support a model similar to that of the keratinocytes in which a substantial fraction of CLIC4 is targeted to the nucleus where it significantly potentiates TGF $\beta$ signaling. Clearly the mice do not manifest the dramatic difference in scarring and fibrosis one might expect if CLIC4 plays a decisive role in potentiating TGF $\beta$ signaling in proximal tubule cells analogous to the data regarding cells of the skin. The absence of an important role for CLIC4 suggests tissue and cell specific patterns of TGF $\beta$ signaling where CLIC4 plays a role in some cell types but not others. Whether CLIC4 plays a meaningful role in this pathway in kidney cells in vivo in other experimental models remains to be determined, but our data indicate it does not have a major impact on the recovery from folic acid induced acute renal failure. 


\section{Changes in expression of CLICs in response to injury in the presence and absence of CLIC4}

We examined the levels of CLICs 1,4 , and 5 in whole kidney homogenates in response to acute folic acid injury in WT and Clic4 null mice. Acute injury did not change level of expression of CLIC4 protein itself during the 48 hours following injury in the WT mice. We did not detect significant up-regulation of CLIC1 or CLIC5A/B in the absence of CLIC4 at baseline, indicating there is not a compensatory up-regulation of these CLICs in the absence of CLIC4 in uninjured kidney, at least at the level of steady state protein in the whole organ. However, we did see intriguing differences in response to injury for both CLICs 1 and 5 in the presence and absence of CLIC4. Expression of CLIC1 is substantially increased over the 48 hours following injury in WT mice, but this up-regulation is greatly impaired in the absence of CLIC4. Expression of both splice variants of CLIC5 are stable following injury in WT mice, but in the absence of CLIC4, there is a significant decrease in expression of CLIC5A and noticeable trend to decreased expression of CLIC5B. These data suggest presence of CLIC4 is permissive for up-regulation of CLIC1 and sustained expression of CLIC5 following acute injury. Since these data are from whole kidney lysates, we cannot know which cell types are responsible for these changes of expression.

\section{Conclusion}

We have shown that Clic4 null mice have increased susceptibility to acute kidney injury induced by folic acid. We found a number of differences in the Clic4 null mice that would be expected to contribute to this increased susceptibility, including small kidneys, fewer glomeruli, a less dense peritubular capillary network, and proteinuria that appears to be primarily of glomerular origin. While we have found some differences in the Clic4 null mice that could plausibly contribute to increased susceptibility to acute kidney injury, the response to acute kidney injury is complex and systemic, and CLIC4 is expressed in many tissues and cell types. Certainly it is possible that other, as of yet unrecognized direct or indirect consequences of the absence of CLIC4, both in renal and in extrarenal tissues, may have a decisive impact on these observations

Our original hypothesis that CLIC4 contributes substantially to fibrosis and long-term kidney scarring following injury is not persuasively supported by our data. We did not find the obvious difference in scarring one would expect if CLIC4 is a major, non-redundant determinant of the intensity and duration of TGF $\beta$ signaling in kidney cells. Furthermore, we did not find nuclear redistribution of CLIC4 in proximal tubule or endothelial cells following injury in the WT mice, and we did not find a significant difference in levels of pSMAD 2 or 3 at 24 or 48 hours following injury between WT and Clic4 null mice. These data strongly challenge the hypothesis that CLIC4 potentiates TGF $\beta$ signaling in the kidney following acute injury.

\section{Abbreviations \\ TGF $\beta$ : Transforming growth factor $\beta$; DAPI: 4',6-diamidino-2-phenylindole; BUN: Blood urea nitrogen; AKI: Acute kidney injury; PCNA: Proliferating cell nuclear antigen.}

\section{Competing interests}

The authors declare that they have no competing interests.

\section{Authors' contributions}

JCE served as the principal investigator and was directly involved in all phases of the work. JB processed the biochemical samples, carried out the western blotting and performed data analysis. PK managed the animals and performed the immunostaining and confocal microscopy. Y-W C also managed the animals, performed the glomerular counting and capillary density assessment. All authors contributed to experimental plan and interpretation and have read and approved the manuscript.

\section{Acknowledgements}

This work was supported by NIH Grant 5RO1HL92131-3. The sponsors had no role in design, collection, interpretation, or publication of this data. We thank Dr. Jeffrey Miner, Washington University School of Medicine, for commenting on the electron micrographs. We thank the Dr. Jan Ryerse of the St. Louis University Research Microscopy Core for assistance with obtaining the con-focal and electron microscopy images.

Received: 13 November 2013 Accepted: 28 March 2014 Published: 3 April 2014

\section{References}

1. Bonventre JV, Yang L: Cellular pathophysiology of ischemic acute kidney injury. J Clin Invest 2011, 121(11):4210-4221.

2. Yang L, Humphreys BD, Bonventre JV: Pathophysiology of acute kidney injury to chronic kidney disease: maladaptive repair. Contrib Nephrol 2011, 174:149-155.

3. Sharfuddin AA, Molitoris BA: Pathophysiology of ischemic acute kidney injury. Nat Rev Nephrol 2011, 7(4):189-200.

4. Wen X, Murugan R, Peng Z, Kellum JA: Pathophysiology of acute kidney injury: a new perspective. Contrib Nephrol 2010, 165:39-45.

5. Bohle A, Mackensen-Haen S, Wehrmann M: Significance of postglomerular capillaries in the pathogenesis of chronic renal failure. Kidney Blood Press Res 1996, 19(3-4):191-195.

6. Yuan HT, Li XZ, Pitera JE, Long DA, Woolf AS: Peritubular capillary loss after mouse acute nephrotoxicity correlates with down-regulation of vascular endothelial growth factor-A and hypoxia-inducible factor-1 alpha. Am J Pathol 2003, 163(6):2289-2301.

7. Ashley RH: Challenging accepted ion channel biology: p64 and the CLIC family of putative intracellular anion channel proteins (Review). Mol Membr Biol 2003, 20(1):1-11.

8. Littler DR, Harrop SJ, Goodchild SC, Phang JM, Mynott AV, Jiang L Valenzuela SM, Mazzanti M, Brown LJ, Breit SN, Curmi PM: The enigma of the CLIC proteins: ion channels, redox proteins, enzymes, scaffolding proteins? FEBS Lett 2010, 584(10):2093-2101.

9. Chuang JZ, Milner TA, Zhu M, Sung CH: A 29 kDa intracellular chloride channel $\mathrm{p} 64 \mathrm{H} 1$ is associated with large dense-core vesicles in rat hippocampal neurons. J Neurosci 1999, 19(8):2919-2928.

10. Duncan RR, Westwood PK, Boyd A, Ashley RH: Rat brain p64H1, expression of a new member of the p64 chloride channel protein family in endoplasmic reticulum. J Biol Chem 1997, 272(38):23880-23886.

11. Edwards JC, Tulk B, Schlesinger PH: Functional expression of p64, an intracellular chloride channel protein. J Membr Biol 1998, 163(2):119-127.

12. Fernandez-Salas E, Sagar M, Cheng C, Yuspa SH, Weinberg WC: p53 and tumor necrosis factor alpha regulate the expression of a mitochondrial chloride channel protein. J Biol Chem 1999, 274(51):36488-36497. 
13. Suh KS, Mutoh M, Mutoh T, Li L, Ryscavage A, Crutchley JM, Dumont RA, Cheng C, Yuspa SH: CLIC4 mediates and is required for Ca2 +-induced keratinocyte differentiation. J Cell Sci 2007, 120(Pt 15):2631-2640.

14. Singh $\mathrm{H}$, Ashley $\mathrm{RH}$ : CLIC4 (p64H1) and its putative transmembrane domain form poorly selective, redox-regulated ion channels. Mol Membr Biol 2007, 24(1):41-52.

15. Littler DR, Assaad NN, Harrop SJ, Brown LJ, Pankhurst GJ, Luciani P, Aguilar MI, Mazzanti M, Berryman MA, Breit SN, Curmi PM: Crystal structure of the soluble form of the redox-regulated chloride ion channel protein CLIC4. FEBS J 2005, 272(19):4996-5007.

16. Arnould T, Mercy L, Houbion A, Vankoningsloo S, Renard P, Pascal T, Ninane $\mathrm{N}$, Demazy C, Raes M: mtCLIC is up-regulated and maintains a mitochondrial membrane potential in mtDNA-depleted L929 cells. FASEB J 2003, 17(14):2145-2147.

17. Ulmasov B, Bruno J, Gordon N, Hartnett ME, Edwards JC: Chloride intracellular channel protein- 4 functions in angiogenesis by supporting acidification of vacuoles along the intracellular tubulogenic pathway. Am J Pathol 2009, 174(3):1084-1096

18. Fernandez-Salas E, Suh KS, Speransky W, Bowers WL, Levy JM, Adams T, Pathak KR, Edwards LE, Hayes DD, Cheng C, Steven AC, Weinberg WC, Yuspa SH: mtCLIC/CLIC4, an organellular chloride channel protein, is increased by DNA damage and participates in the apoptotic response to p53. Mol Cell Biol 2002, 22(11):3610-3620.

19. Suh KS, Mutoh M, Gerdes M, Crutchley JM, Mutoh T, Edwards LE, Dumont RA, Sodha P, Cheng C, Glick A, Yuspa SH: Antisense suppression of the chloride intracellular channel family induces apoptosis, enhances tumo necrosis factor \{alpha\}-induced apoptosis, and inhibits tumor growth. Cancer Res 2005, 65(2):562-571.

20. Suh KS, Mutoh M, Nagashima K, Fernandez-Salas E, Edwards LE, Hayes DD, Crutchley JM, Marin KG, Dumont RA, Levy JM, Cheng C, Garfield S, Yuspa $\mathrm{SH}$ : The organellular chloride channel protein CLIC4/mtCLIC translocates to the nucleus in response to cellular stress and accelerates apoptosis. J Biol Chem 2004, 279(6):4632-4641.

21. Suginta W, Karoulias N, Aitken A, Ashley RH: Chloride intracellular channel protein CLIC4 (p64H1) binds directly to brain dynamin I in a complex containing actin, tubulin and 14-3-3 isoforms. Biochem J 2001, 359(Pt 1):55-64

22. Berryman MA, Goldenring JR: CLIC4 is enriched at cell-cell junctions and colocalizes with AKAP350 at the centrosome and midbody of cultured mammalian cells. Cell Motil Cytoskeleton 2003, 56(3):159-172.

23. Yao Q, Qu X, Yang Q, Wei M, Kong B: CLIC4 mediates TGF-beta1-induced fibroblast-to-myofibroblast transdifferentiation in ovarian cancer. Oncol Rep 2009, 22(3):541-548.

24. Tung JJ, Hobert O, Berryman M, Kitajewski J: Chloride intracellular channel 4 is involved in endothelial proliferation and morphogenesis in vitro. Angiogenesis 2009, 12(3):209-220.

25. Bohman S, Matsumoto T, Suh K, Dimberg A, Jakobsson L, Yuspa S, Claesson-Welsh L: Proteomic analysis of vascular endothelial growth factor-induced endothelial cell differentiation reveals a role for chloride intracellular channel 4 (CLIC4) in tubular morphogenesis. J Biol Chem 2005, 280(51):42397-42404

26. Shukla A, Malik M, Cataisson C, Ho Y, Friesen T, Suh KS, Yuspa SH: TGF-beta signalling is regulated by Schnurri-2-dependent nuclear translocation of CLIC4 and consequent stabilization of phospho-Smad2 and 3. Nat Cell Biol 2009, 11(6):777-784.

27. Padmakumar VC, Speer K, Pal-Ghosh S, Masiuk K, Ryscavage A, Dengler S, Hwang S, Edwards J, Coppola V, Tessarollo L, Stepp MA, Yuspa SH: Spontaneous skin erosions and reduced skin and corneal wound healing characterize CLIC4 (NULL) mice. Am J Pathol 2012, 181(1):74-84.

28. Long DA, Price KL, loffe E, Gannon CM, Gnudi L, White KE, Yancopoulos GD, Rudge JS, Woolf AS: Angiopoietin-1 therapy enhances fibrosis and inflammation following folic acid-induced acute renal injury. Kidney Int 2008, 74(3):300-309.

29. Wang W, Koka V, Lan HY: Transforming growth factor-beta and Smad signalling in kidney diseases. Nephrology (Carlton) 2005, 10(1):48-56.

30. Qi W, Chen X, Poronnik P, Pollock CA: Transforming growth factor-beta/ connective tissue growth factor axis in the kidney. Int J Biochem Cell Biol 2008, 40(1):9-13.

31. Stahl PJ, Felsen D: Transforming growth factor-beta, basement membrane, and epithelial-mesenchymal transdifferentiation: implications for fibrosis in kidney disease. Am J Pathol 2001, 159(4):1187-1192.
32. Ulmasov B, Bruno J, Woost PG, Edwards JC: Tissue and subcellular distribution of CLIC1. BMC Cell Biol 2007, 8:8.

33. Fassi A, Sangalli F, Maffi R, Colombi F, Mohamed El, Brenner BM, Remuzzi G, Remuzzi A: Progressive glomerular injury in the MWF rat is predicted by inborn nephron deficit. J Am Soc Nephro/ 1998, 9(8):1399-1406.

34. Bankir L, Hollenberg NK: In vivo staining of the kidney with Alcian blue: an adjunct to morphological and physiological studies. Ren Physiol 1983, 6(3):151-155.

35. Redfern BG, David Wise L, Spence S: An alternative Alcian blue dye variant for the evaluation of fetal cartilage. Birth Defects Res B Dev Reprod Toxicol 2007, 80(3):171-176.

36. Doi K, Okamoto K, Negishi K, Suzuki Y, Nakao A, Fujita T, Toda A, Yokomizo T, Kita Y, Kihara Y, Isshi S, Shimizu T, Noiri E: Attenuation of folic acidinduced renal inflammatory injury in platelet-activating factor receptordeficient mice. Am J Pathol 2006, 168(5):1413-1424.

37. Lin J, Patel SR, Cheng X, Cho EA, Levitan I, Ullenbruch M, Phan SH, Park JM, Dressler GR: Kielin/chordin-like protein, a novel enhancer of BMP signaling, attenuates renal fibrotic disease. Nat Med 2005, 11(4):387-393.

38. Imgrund M, Grone E, Grone HJ, Kretzler M, Holzman L, Schlondorff D, Rothenpieler UW: Re-expression of the developmental gene Pax-2 during experimental acute tubular necrosis in mice 1. Kidney Int 1999, 56(4):1423-1431.

39. Armitage P: Statistical methods in medical research. Oxford: Blackwell Scientific Publications; 1971.

40. Edwards JC: A novel p64-related Cl- channel: subcellular distribution and nephron segment-specific expression. Am J Physiol 1999, 276(3 Pt 2):F398-F408.

41. Tulk BM, Edwards JC: NCC27, a homolog of intracellular Cl- channel p64, is expressed in brush border of renal proximal tubule. Am J Physio/ 1998, 274(6 Pt 2):F1140-F1149.

42. Pierchala BA, Munoz MR, Tsui CC: Proteomic analysis of the slit diaphragm complex: CLIC5 is a protein critical for podocyte morphology and function. Kidney Int 2010, 78(9):868-882.

43. Wegner B, Al-Momany A, Kulak SC, Kozlowski K, Obeidat M, Jahroudi N, Paes J, Berryman M, Ballermann BJ: CLIC5A, a component of the ezrinpodocalyxin complex in glomeruli, is a determinant of podocyte integrity. Am J Physiol Renal Physiol 2010, 298(6):F1492-F1503.

44. Edwards JC, Kapadia S: Regulation of the bovine kidney microsomal chloride channel p64 by p59fyn, a Src family tyrosine kinase. J Biol Chem 2000, 275(41):31826-31832.

45. Long DA, Woolf AS, Suda T, Yuan HT: Increased renal angiopoietin-1 expression in folic acid-induced nephrotoxicity in mice. J Am Soc Nephrol 2001, 12(12):2721-2731.

46. Hsu RK, Hsu CY: Proteinuria and reduced glomerular filtration rate as risk factors for acute kidney injury. Curr Opin Nephrol Hypertens 2011 20(3):211-217

47. Long DA, Kolatsi-Joannou M, Price KL, Dessapt-Baradez C, Huang JL, Papakrivopoulou E, Hubank M, Korstanje R, Gnudi L, Woolf AS: Albuminuria is associated with too few glomeruli and too much testosterone. Kidney Int 2013, 83(6):1118-1129.

48. Puelles VG, Hoy WE, Hughson MD, Diouf B, Douglas-Denton RN, Bertram JF: Glomerular number and size variability and risk for kidney disease. Curr Opin Nephrol Hypertens 2011, 20(1):7-15.

49. Anderson S, Eldadah B, Halter JB, Hazzard WR, Himmelfarb J, Horne FM, Kimmel PL, Molitoris BA, Murthy M, O'Hare AM, Schmader KE, High KP: Acute kidney injury in older adults. J Am Soc Nephrol 2011, 22(1):28-38.

\section{doi:10.1186/1471-2369-15-54}

Cite this article as: Edwards et al: Absence of chloride intracellular channel 4 (CLIC4) predisposes to acute kidney injury but has minimal impact on recovery. BMC Nephrology 2014 15:54. 